\title{
openheart Dual antiplatelet therapy for secondary prevention of coronary artery disease
}

\author{
Sophie Degrauwe, ${ }^{1}$ Thomas Pilgrim, ${ }^{2}$ Adel Aminian, ${ }^{3}$ Stephane Noble, ${ }^{4}$ \\ Pascal Meier, ${ }^{4}$ Juan F Iglesias ${ }^{1}$
}

To cite: Degrauwe S, Pilgrim T, Aminian A, et al. Dual antiplatelet therapy for secondary prevention of coronary artery disease. Open Heart 2017;4:e000651. doi:10.1136/ openhrt-2017-000651

Received 3 May 2017 Revised 31 July 2017 Accepted 1 August 2017

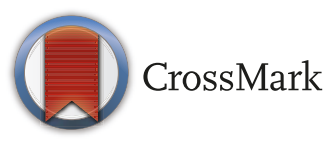

'Department of Cardiology, Lausanne University Hospital, Lausanne, Switzerland ${ }^{2}$ Department of Cardiology, Bern University Hospital, Bern, Switzerland

${ }^{3}$ Division of Cardiology, Charleroi University Hospital, Charleroi, Belgium

${ }^{4}$ Division of Cardiology, Geneva University Hospital, Geneva, Switzerland

Correspondence to Dr Juan F Iglesias; juan. fernando.iglesias@gmail.com

\section{ABSTRACT}

Dual antiplatelet therapy (DAPT) combining aspirin and a P2Y ${ }_{12}$ receptor inhibitor has been consistently shown to reduce recurrent major adverse cardiovascular events (MACE) in patients with acute coronary syndrome (ACS) or undergoing percutaneous coronary intervention (PCl) for stable coronary artery disease (CAD) compared with aspirin monotherapy, but at the expense of an increased risk of major bleeding. Nevertheless, the optimal duration of DAPT for secondary prevention of CAD remains uncertain, owing to the conflicting results of several large randomised trials. Among patients with stable CAD undergoing $\mathrm{PCI}$ with drug-eluting stents (DES), shorter durations of DAPT (3-6 months) were shown non-inferior to 12 or 24 months duration with respect to MACE, but reduced the rates of major bleeding. Contrariwise, prolonged DAPT durations (18-48 months) reduced the incidence of myocardial infarction and stent thrombosis, but at a cost of an increased risk of major bleeding and all-cause mortality. Until more evidence becomes available, the choice of optimal DAPT regimen and duration for patients with CAD requires a tailored approach based on the patient clinical presentation, baseline risk profile and management strategy. Future studies are however needed to identify patients who may derive benefit from shortened or extended DAPT courses for secondary prevention of CAD based on their individual ischaemic and bleeding risk. Based on limited evidence, 12 months duration of DAPT is currently recommended in patients with ACS irrespective of their management strategy, but large ongoing randomised trials are currently assessing the efficacy and safety of a short-term DAPT strategy (3-6 months) for patients with ACS undergoing $\mathrm{PCI}$ with newer generation DES. Finally, several ongoing, large-scale, randomised trials are challenging the current concept of DAPT by investigating $\mathrm{P}_{2} \mathrm{Y}_{12}$ receptor inhibitors as single antiplatelet therapy and may potentially shift the paradigm of antiplatelet therapy after $\mathrm{PCl}$ in the near future. This article provides a contemporary stateof-the-art review of the current evidence on DAPT for secondary prevention of patients with CAD and its future perspectives.

\section{INTRODUCTION}

Antiplatelet therapy represents the mainstay of the pharmacological treatment and secondary prevention of coronary artery disease (CAD). Compared with placebo, antiplatelet therapy has been shown to reduce recurrent major adverse cardiovascular events (MACE) among patients with stable CAD or acute coronary syndrome (ACS). ${ }^{1}$ Dual antiplatelet therapy (DAPT) provides more intense platelet inhibition than single antiplatelet therapy resulting in incremental reductions in the risk of thrombotic events after percutaneous coronary intervention (PCI) or ACS, but it has been associated with an increased risk of major bleeding. ${ }^{2-5}$ The choice of optimal DAPT regimen and duration for patients with CAD requires a tailored approach based on the patient clinical presentation, baseline risk profile and management strategy. However, the selection of patients who might derive benefit from shorter or extended DAPT duration remains a matter of debate. This article provides a contemporary state-of-the-art review of the current evidence on DAPT for secondary prevention of patients with CAD and its future perspectives.

\section{ANTIPLATELET AGENTS}

Platelet inhibition plays a central role for treatment and prevention of short- and long-term atherothrombotic events in patients with CAD. Oral antiplatelet agents for secondary prevention of patients with CAD include the cyclo-oxygenase-1 inhibitor aspirin, and the platelet adenosine diphosphate $\mathrm{P}_{2} \mathrm{Y}_{12}$ receptor inhibitors clopidogrel, prasugrel and ticagrelor. Aspirin and clopidogrel have been studied across the whole spectrum of $\mathrm{CAD}$, whereas the more recent potent $\mathrm{P}_{12}$ platelet receptor inhibitors prasugrel and ticagrelor have been evaluated in patients with ACS. The main characteristics, mechanisms of action and indications of oral antiplatelet agents used for secondary prevention of CAD are summarised in table 1 . Although there are several potential combinations of antiplatelet agents, DAPT refers to the therapy combining aspirin and a $\mathrm{P}_{2} \mathrm{Y}_{12}$ receptor inhibitor (clopidogrel, prasugrel or ticagrelor). DAPT has been shown to reduce recurrent major ischaemic events in patients 


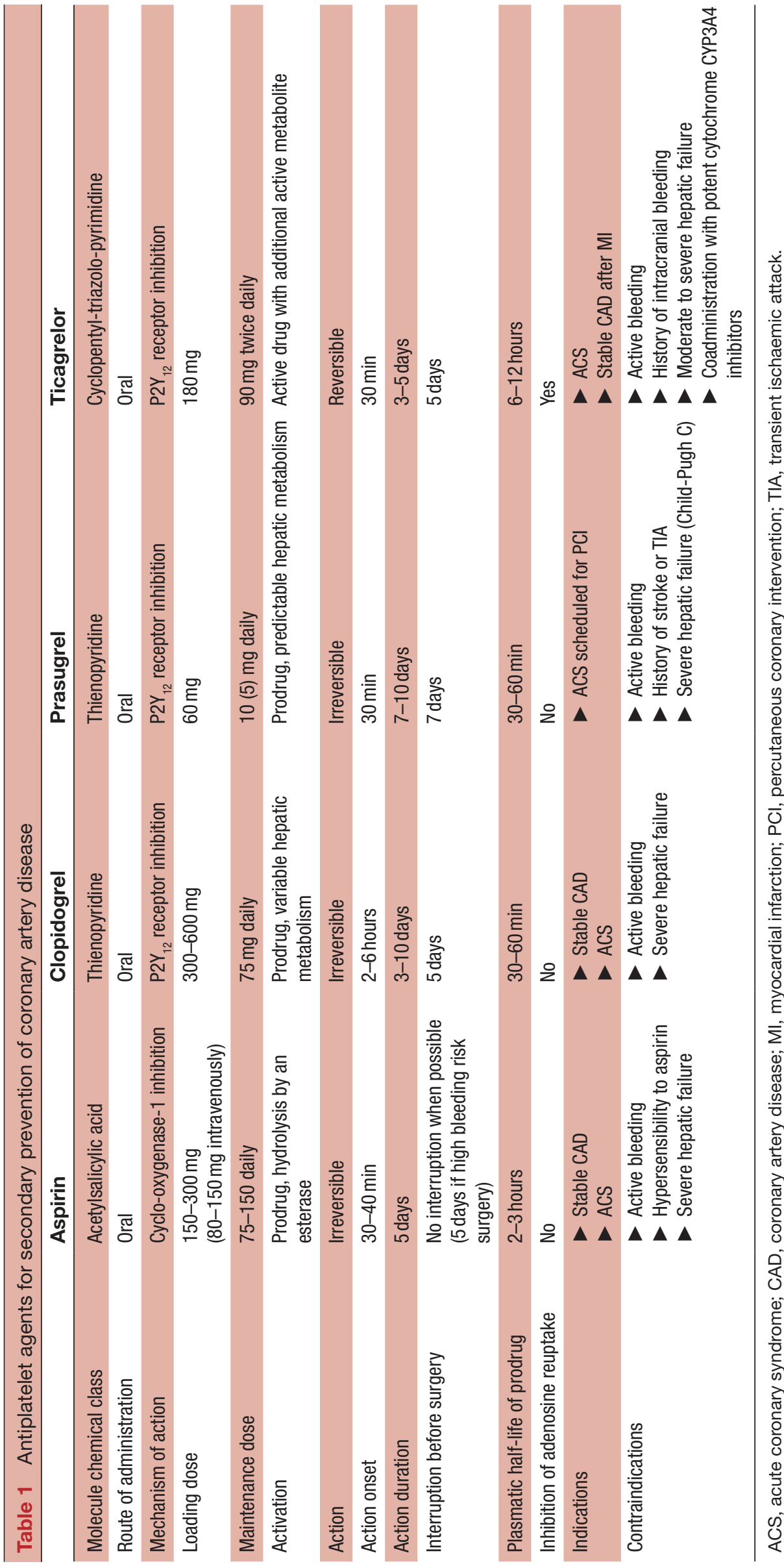


with ACS or undergoing PCI, ${ }^{1}$ at the expense of an unavoidable increased risk of major bleeding compared with single antiplatelet therapy. A personalised approach based on the patient clinical presentation (stable CAD or ACS), baseline ischaemic and bleeding risk profiles, and management strategy (conservative treatment, PCI or coronary artery bypass graft $(\mathrm{CABG}))$ is currently advocated. ${ }^{2-5}$

\section{STABLE CAD}

Aspirin remains the cornerstone for secondary prevention of patients with stable CAD, irrespective of the management strategy. In a large meta-analysis including 16 secondary prevention trials and 17000 high-risk patients, low-dose aspirin ( $75-150 \mathrm{mg} /$ day) was associated with a $20 \%$ relative risk reduction in MACE (cardiovascular (CV) death or non-fatal myocardial infarction (MI)) (rate ratio $0.80,95 \%$ CI 0.73 to 0.88 ), a $31 \%$ relative risk reduction in MI (RR $0.69,95 \%$ CI 0.60 to 0.80 ) and a $22 \%$ relative risk reduction in ischaemic stroke (RR 0.78 , $95 \%$ CI 0.61 to 0.99 ), at the expense of an increased risk of haemorrhagic stroke (RR $1.67,95 \%$ CI 0.97 to 2.90) and major extracranial bleeding (RR 2.69, 95\% CI 1.25 to 5.76). ${ }^{1}$ Aspirin marginally reduced $\mathrm{CV}$ mortality (RR $0.91,95 \%$ CI 0.82 to $1.00, \mathrm{p}=0.06$ ), resulting in a $10 \%$ relative risk reduction in all-cause mortality (RR $0.90,95 \% \mathrm{CI}$ 0.82 to $0.99, \mathrm{p}=0.02) .{ }^{1}$ At variance of the antiplatelet effects, the gastrointestinal side effects of aspirin increase at higher doses. The optimal risk:benefit ratio appears to be achieved with an aspirin dosage of 75-150 mg daily. ${ }^{26}$

The Clopidogrel versus Aspirin in Patients at Risk of Ischaemic Events (CAPRIE) trial compared antiplatelet therapy with clopidogrel (75 mg daily) versus aspirin (325 mg daily) in 19185 patients with atherosclerotic cardiovascular disease (ACVD) (recent ischaemic stroke, recent MI or symptomatic peripheral arterial disease $(\mathrm{PAD}))^{7}$ Compared with aspirin, long-term administration of clopidogrel (median follow-up 2 years) was associated with significant risk reductions in the combined endpoint of $\mathrm{CV}$ death, MI or ischaemic stroke $(5.32 \%$ per year vs $5.83 \%$ per year, relative risk reduction $8.7 \%, 95 \%$ CI 0.3 to $16.5, \mathrm{p}=0.04$ ) without significantly increased risk of severe intracranial $(0.31 \%$ vs $0.43 \%$, $\mathrm{p}=0.23)$ and gastrointestinal bleedings $(0.49 \%$ vs $0.71 \%$, $\mathrm{p}=0.05){ }^{7}$ Importantly, the superiority of clopidogrel over aspirin was mainly driven by a reduction of events in the PAD, but not MI, subgroup. ${ }^{7}$ Although potent P2Y 12 receptor inhibitors have shown superior efficacy than clopidogrel in patients with ACS, there is currently little evidence to support the use of prasugrel and ticagrelor in patients with stable CAD.

According to current guidelines, long-term low-dose aspirin is recommended in all patients with stable CAD (class I).${ }^{26}$ Clopidogrel (75 mg daily) is indicated as an alternative in case of aspirin intolerance (class I). ${ }^{2}$ Alternatively, aspirin desensitisation may also be considered in patients with a compelling need for aspirin therapy.

\section{Conservative treatment}

Data supporting the benefits of long-term DAPT in unselected patients with stable $\mathrm{CAD}$ are limited. The Clopidogrel for High Atherothrombotic Risk and Ischemic Stabilisation, Management and Avoidance (CHARISMA) trial randomly assigned 15603 patients with documented ACVD (CAD, cerebrovascular disease or PAD) or multiple atherothrombotic risk factors to receive clopidogrel ( $75 \mathrm{mg}$ daily) versus placebo in addition to low-dose aspirin (75-162 mg daily). ${ }^{8}$ Overall, rates of the primary composite endpoint (CV death, MI or stroke) were similar in the clopidogrel plus aspirin and aspirin alone groups after a median follow-up of 28 months $(6.8 \%$ vs $7.3 \%, 95 \%$ CI 0.83 to $1.05, \mathrm{p}=0.22$ ), despite a marginally increased risk of severe bleeding among patients treated with DAPT ( $1.7 \%$ vs $1.3 \%$, RR $1.25,95 \%$ CI 0.97 to 1.61 , $\mathrm{p}=0.09) .{ }^{8}$ In the subgroup of patients with multiple risk factors, the rates of the primary endpoint $(6.6 \%$ vs $5.5 \%$, RR 1.2, 95\% CI 0.91 to $1.59, \mathrm{p}=0.20)$ and CV death were higher in clopidogrel-treated patients $(3.9 \%$ vs $2.2 \%$, $\mathrm{p}=0.01$ ). In the prespecified subgroup of patients with clinically evident ACVD $(n=12153)$, there was a marginally significant reduction in the primary ischaemic endpoint in the clopidogrel plus aspirin group $(6.9 \%$ vs $7.9 \%$, RR $0.88,95 \%$ CI 0.77 to $0.998, \mathrm{p}=0.046)$, whereas asymptomatic patients with multiple risk factors only $(n=3284)$ assigned to clopidogrel plus aspirin experienced a $20 \%$ relative risk increase in the rate of primary ischaemic events $(6.6 \%$ vs $5.5 \%, \mathrm{p}=0.20)$ and a significant increase in rates of all-cause $(5.4 \%$ vs $3.8 \%, \mathrm{p}=0.04)$ and $\mathrm{CV}$ death $(3.9 \%$ vs $2.2 \%, \mathrm{p}=0.01)$, compared with those assigned to aspirin alone. ${ }^{8}$ In a posthoc subgroup analysis of 9478 patients with prior MI, ischaemic stroke or $\mathrm{PAD}$, rates of the primary composite endpoint $(7.3 \%$ vs $8.8 \%$, HR $0.83,95 \%$ CI 0.72 to $0.96, \mathrm{p}=0.01$ ) and hospitalisations for ischaemia ( $11.4 \%$ vs $13.2 \%$, HR $0.86,95 \%$ CI 0.76 to 0.96 , $\mathrm{p}=0.008$ ) were significantly lower in the clopidogrel plus aspirin arm than in the aspirin alone arm. ${ }^{9}$ In patients treated with DAPT, there was a significantly increased risk of moderate bleeding $(2.0 \%$ vs $1.3 \%$, HR $1.60,95 \%$ CI 1.16 to $2.20, \mathrm{p}=0.004$ ) with no significant difference in rates of severe bleeding ( $1.7 \%$ vs $1.5 \%$, HR $1.12,95 \%$ CI 0.81 to $1.53, \mathrm{p}=0.50) .^{9}$

Routine DAPT is currently not recommended for patients with stable CAD without history of ACS, PCI or CABG within 12 months (class III). ${ }^{2}{ }^{6}$ Results from the CHARISMA trial suggest the potential benefits of DAPT with aspirin and clopidogrel beyond aspirin alone in a subgroup of patients with stable $\mathrm{CAD}$ and at high risk of CV events $^{9}$ (figure 1 ).

\section{Percutaneous coronary intervention}

The combination of aspirin and $\mathrm{P}_{2} \mathrm{Y}_{12}$ receptor inhibitor therapy remains the mainstay of pharmacological treatment for patients undergoing PCI with bare metal stents (BMS) or drug-eluting stents (DES). Among patients undergoing PCI, DAPT with aspirin and a P2Y ${ }_{12}$ receptor antagonist (ticlopidine) during 4-6 weeks significantly 


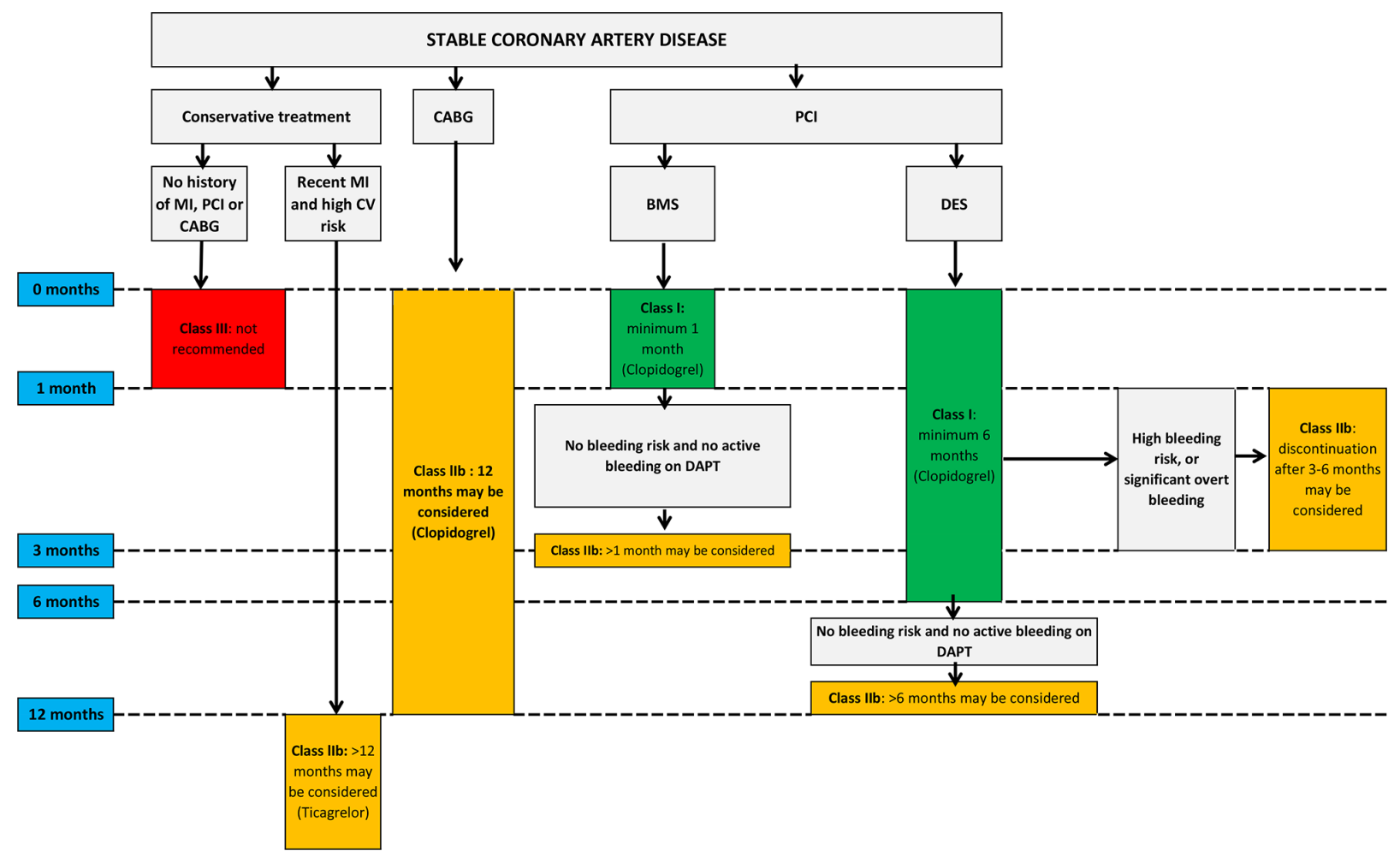

Figure $1 \mathrm{P}_{2} \mathrm{Y}_{12}$ receptor inhibitor therapy for secondary prevention of patients with stable coronary artery disease. BMS, bare metal stent; CABG, coronary artery bypass graft surgery; CV, cardiovascular; DAPT, dual antiplatelet therapy; DES, drug-eluting stent; MI, myocardial infarction; $\mathrm{PCl}$, percutaneous coronary intervention.

reduced rates of MACE compared with combined aspirin and oral anticoagulation (OAC) therapy ${ }^{10-13}$ or aspirin single antiplatelet therapy, ${ }^{12}$ and decreased major bleeding rates compared with combination of aspirin and OAC. ${ }^{10-13}$ However, prolonged DAPT duration increases the risk of major bleeding compared with aspirin alone, which has been strongly related to an increased risk of short ${ }^{14}$ and long-term mortality. ${ }^{15}$ The Clopidogrel for the Reduction of Events during Observation (CREDO) trial randomly assigned 2116 patients scheduled for elective PCI or deemed at high likelihood of undergoing PCI to receive clopidogrel for up to 1 year (preceded by a $300 \mathrm{mg}$ loading dose) or for 1 month (without loading dose), in addition to aspirin. ${ }^{16}$ At 1 year, long-term clopidogrel therapy was associated with a $27 \%$ relative risk reduction in the combined ischaemic endpoint (death, MI or stroke) (95\% CI 3.9\% to $44.4 \%, \mathrm{p}=0.02$; absolute reduction 3\%) compared with a short clopidogrel regimen, at the expense of a marginally increased risk of major bleeding $(8.8 \%$ vs $6.7 \%, \mathrm{p}=0.07) .{ }^{16}$

While there is general consensus on 1-month DAPT duration after BMS implantation, ${ }^{236}$ the optimal duration of DAPT after DES implantation remains a matter of debate. Newer generation DES with thinner strut thickness, biocompatible or biodegradable polymer coatings, and reduced sirolimus-analogue antiproliferative drug doses have been developed to improve arterial healing and reduce the risk of late thrombotic adverse events, which may potentially mitigate the need for prolonged intense platelet inhibition after DES implantation. ${ }^{17}$ The conflicting evidence concerning optimal DAPT duration after DES implantation is reflected in the contradictory results of 12 randomised controlled trials (RCT) performed to date to address this challenging and unsolved clinical issue. ${ }^{18-29}$ The inconsistent results may in part be explained by important differences in study designs, patient risk profiles, DAPT strategies, DES types implanted and study primary endpoints. Most of the trials have been characterised by slow enrolment, inclusion of low-risk patients and limited statistical power due to sample size estimates based on large event rates reductions or non-inferiority margins, coupled with lower than anticipated observed event rates. In addition, several study designs combined both efficacy and safety outcomes into a single primary endpoint, thus confusing the relative risks and benefits of individual ischaemic and bleeding outcomes.

Most of contemporary studies have compared either shorter (3-6 months) or longer (18-48 months) courses of DAPT versus 12-month DAPT duration, which has traditionally been considered as the recommended DAPT duration for most patients after DES implantation. Seven RCTs have consistently reported similar ischaemic outcomes but significantly reduced major bleeding rates with shorter 3- or 6-month compared with longer ( $\geq 12$ months) DAPT durations after DES implantation ${ }^{18-24}$ (table 2). Conversely, with the exception of the DAPT study, ${ }^{25}$ four RCTs have consistently failed to demonstrate a reduction in ischaemic events with DAPT prolongation beyond 12 months (up to 
Table 2 Overview of major randomised controlled trials comparing short-term (3-6 months) versus long-term ( $\geq 12$ months) DAPT duration after drug-eluting stent implantation

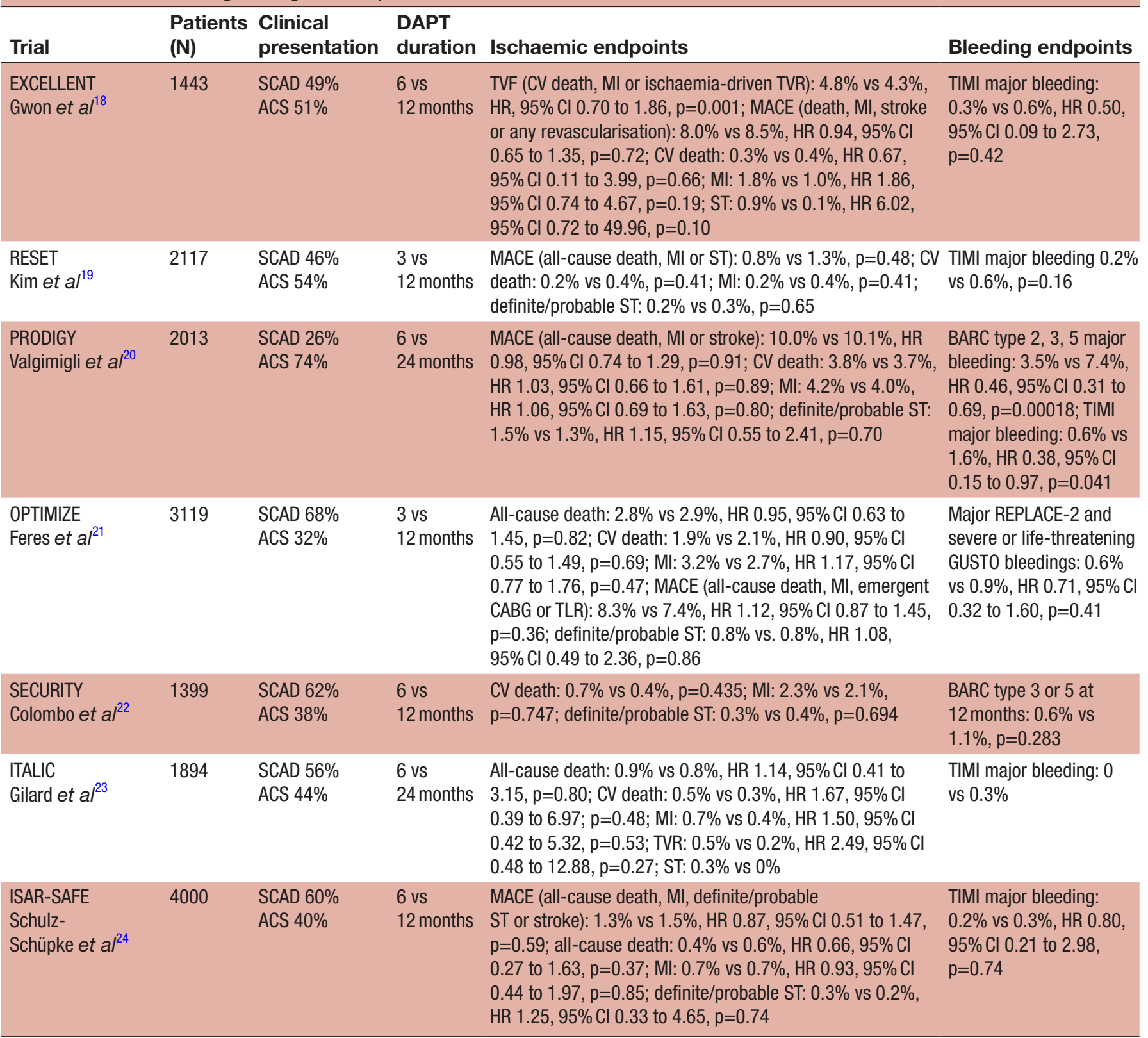

ACS, acute coronary syndrome; BARC, Bleeding Academic Research Consortium; CABG, coronary artery bypass graft surgery; CV, cardiovascular; DAPT, dual antiplatelet therapy; GUSTO, Global Utilization of Streptokinase and Tissue Plasminogen Activator for Occluded Coronary Arteries; MACCE, major adverse cardiac and cerebrovascular events; MACE, major adverse cardiovascular events; MI, myocardial infarction; REPLACE, Randomised Evaluation of PCI Linking Angiomax to Reduced Clinical Events; SCAD, stable coronary artery disease; ST, stent thrombosis; TIMI, thrombolysis in myocardial infarction; TLR, target lesion revascularisation; TVF, target vessel failure; TVR, target vessel revascularisation.

48 months), as compared with 12-month $\mathrm{DAPT}^{26-29}$ (table 3).

The Dual Antiplatelet Therapy (DAPT) study randomly assigned 9961 patients who underwent PCI with DES to continue thienopyridine therapy or to receive placebo for 18 months in addition to aspirin, after 12 months of DAPT combining aspirin and a thienopyridine (clopidogrel or prasugrel). Prolonged DAPT (30 months) after DES significantly reduced rates of stent thrombosis (ST) $(0.4 \%$ vs $1.4 \%$, HR 0.29 , 95\% CI 0.17 to
$0.48, \mathrm{p}<0.001), \operatorname{MACE}(4.3 \%$ vs $5.9 \%$, HR $0.71,95 \% \mathrm{CI}$ 0.59 to $0.85, \mathrm{p}<0.001)$ and $\mathrm{MI}(2.1 \%$ vs $4.1 \%$, HR 0.47 , $\mathrm{p}<0.001)$, compared with 12-month DAPT duration. ${ }^{25}$ Continued thienopyridine therapy beyond 12 months was associated with marginally increased rates of all-cause mortality $(2.0 \%$ vs $1.5 \%$, HR $1.36,95 \%$ CI 1.00 to 1.85 , $\mathrm{p}=0.05)$ and a significantly increased risk of moderate or severe bleeding $(2.5 \%$ vs $1.6 \%, \mathrm{p}=0.001)$ compared with 12-month DAPT. ${ }^{25}$ Finally, there was an increased risk of ST and MI in both treatment groups during the 3 months 
Table 3 Overview of major randomised controlled trials comparing extended versus standard (12 months) dual antiplatelet therapy duration after drug-eluting stent implantation

\begin{tabular}{|c|c|c|c|c|c|}
\hline Trial & $\begin{array}{l}\text { Patients } \\
\text { (N) }\end{array}$ & $\begin{array}{l}\text { Clinical } \\
\text { presentation }\end{array}$ & $\begin{array}{l}\text { DAPT } \\
\text { duration }\end{array}$ & Ischaemic endpoints & $\begin{array}{l}\text { Bleeding } \\
\text { endpoints }\end{array}$ \\
\hline $\begin{array}{l}\text { REAL-LATE/ } \\
\text { ZEST-LATE } \\
\text { Park et } a l^{26}\end{array}$ & 2701 & $\begin{array}{l}\text { SCAD } 38 \% \\
\text { ACS } 62 \%\end{array}$ & $\begin{array}{l}36 \text { vs } \\
12 \text { months }\end{array}$ & $\begin{array}{l}\text { MACE (CV death, MI): } 1.8 \% \text { vs } 1.2 \%, \mathrm{HR} 1.65,95 \% \mathrm{Cl} 0.80 \text { to } \\
3.36, p=0.17 \text {; all-cause death: } 1.6 \% \text { vs } 1.4 \%, \mathrm{HR} 1.52,95 \% \mathrm{Cl} \\
0.75 \text { to } 3.50, p=0.24 ; \text { Ml: } 0.8 \% \text { vs } 0.7 \%, \mathrm{HR} 1.41,95 \% \mathrm{Cl} \\
0.54 \text { to } 3.71, p=0.49 \text {; definite ST: } 0.4 \% \text { vs. } 0.4 \%, \mathrm{HR} 1.23 \\
95 \% \text { Cl } 0.33 \text { to } 4.58, p=0.76\end{array}$ & $\begin{array}{l}\text { TIMI major bleeding: } \\
0.2 \% \text { vs } 0.1 \% \text {, HR } 2.96 \\
95 \% \mathrm{Cl} 0.31 \text { to } 28.46 \\
\mathrm{p}=0.35\end{array}$ \\
\hline $\begin{array}{l}\text { ARCTIC- } \\
\text { Interruption } \\
\text { Collet et } a l^{28}\end{array}$ & 1259 & STEMI $0 \%$ & $\begin{array}{l}18-30 \text { vs } \\
12 \text { months }\end{array}$ & $\begin{array}{l}\text { MACE (death, MI, ST, stroke or urgent revascularisation): } 4.0 \% \\
\text { vs } 4.0 \%, \mathrm{HR} 1.17,95 \% \mathrm{Cl} 0.68 \text { to } 2.03, \mathrm{p}=0.58 \text {; all-cause } \\
\text { death: } 1.0 \% \text { vs } 1.0 \%, \mathrm{HR} 1.32,95 \% \mathrm{Cl} 0.49 \text { to } 3.55, \mathrm{p}=0.58 \text {; } \\
\mathrm{Ml}: 1.0 \% \text { vs } 1.0 \%, \mathrm{HR} 1.04,95 \% \mathrm{Cl} 0.41 \text { to } 2.62, \mathrm{p}=0.94 ; \mathrm{ST} \text { or } \\
\text { any urgent revascularisation: } 1.0 \% \text { vs } 2.0 \%, \mathrm{HR} 1.30,95 \% \mathrm{Cl} \\
0.51 \text { to } 3.30, \mathrm{p}=0.58\end{array}$ & $\begin{array}{l}\text { STEEPLE major } \\
\text { bleeding: } 1.0 \% \\
\text { vs }<0.5 \%, \mathrm{HR} \\
0.15,95 \% \text { Cl } 0.02 \text { to } \\
1.20, \mathrm{p}=0.07\end{array}$ \\
\hline $\begin{array}{l}\text { DES LATE } \\
\text { Lee et } a l^{27}\end{array}$ & 5045 & $\begin{array}{l}\text { SCAD 39\% } \\
\text { ACS } 61 \%\end{array}$ & $\begin{array}{l}36 \text { vs } \\
12 \text { months }\end{array}$ & $\begin{array}{l}\text { MACE (cardiac death, Ml or stroke): } 2.6 \% \text { vs } 2.4 \% \text {, HR } 0.94 \text {, } \\
95 \% \mathrm{Cl} 0.66 \text { to } 1.35, \mathrm{p}=0.75 \text {; all-cause death: } 2.0 \% \text { vs } 1.4 \% \text {, } \\
\text { HR } 0.71,95 \% \mathrm{Cl} 0.45 \text { to } 1.10, p=0.12 ; \text { MI } 0.8 \% \text { vs } 1.2 \%, \mathrm{HR} \\
1.43,95 \% \mathrm{Cl} 0.80 \text { to } 2.58, \mathrm{p}=0.23 \text {; definite } \mathrm{ST}: 0.3 \% \text { vs } 0.5 \% \text {, } \\
\text { HR } 1.59,95 \% \mathrm{Cl} 0.61 \text { to } 4.09, \mathrm{p}=0.34\end{array}$ & $\begin{array}{l}\text { TIMI major bleeding: } \\
1.4 \% \text { vs } 1.1 \% \text {, HR } 0.71 \\
95 \% \mathrm{Cl} 0.42 \text { to } 1.20 \\
p=0.20\end{array}$ \\
\hline $\begin{array}{l}\text { DAPT } \\
\text { Mauri et }\left.a\right|^{30}\end{array}$ & 9961 & $\begin{array}{l}\text { SCAD } 57 \% \\
\text { ACS } 43 \%\end{array}$ & $\begin{array}{l}30 \text { vs } \\
12 \text { months }\end{array}$ & $\begin{array}{l}\text { MACCE: } 4.3 \% \text { vs } 5.9 \%, \mathrm{HR} 0.71,95 \% \mathrm{Cl} 0.59 \text { to } 0.85, \mathrm{p}<0.001 \text {; } \\
\text { Ml: } 2.1 \% \text { vs } 4.1 \%, \mathrm{HR} 0.47, \mathrm{p}<0.001 ; \mathrm{ST}: 0.4 \% \text { vs } 1.4 \%, \mathrm{HR} \\
0.29,95 \% \mathrm{Cl} 0.17 \text { to } 0.48, \mathrm{p}<0.001\end{array}$ & $\begin{array}{l}\text { GUSTO moderate or } \\
\text { severe bleeding: } 2.5 \% \\
\text { vs } 1.6 \%, p=0.001 \\
\text { BARC type } 2,3 \text { or } 5 \text { : } \\
5.6 \% \text { vs } 2.9 \%, p<0.001\end{array}$ \\
\hline $\begin{array}{l}\text { OPTIDUAL } \\
\text { Helft et } a l^{29}\end{array}$ & 1385 & $\begin{array}{l}\text { SCAD } 64 \% \\
\text { ACS } 36 \%\end{array}$ & $\begin{array}{l}48 \text { vs } \\
12 \text { months }\end{array}$ & $\begin{array}{l}\text { All-cause death: } 2.3 \% \text { vs } 3.5 \%, \mathrm{HR} 0.65,95 \% \mathrm{Cl} 0.34 \text { to } 1.22 \text {, } \\
\mathrm{p}=0.18 \text {; Ml: } 1.6 \% \text { vs } 2.3 \% \text {, HR } 0.67,95 \% \mathrm{Cl} 0.31 \text { to } 1.44, \\
p=0.31 \text {; definite/probable ST: } 0.4 \% \text { vs } 0.1 \%, \mathrm{HR} 2.97,95 \% \mathrm{Cl} \\
0.31 \text { to } 28.53, p=0.35\end{array}$ & $\begin{array}{l}\text { ISTH major bleeding: } \\
2.0 \% \text { vs } 2.0 \% \text {, HR } 0.98 \text {, } \\
95 \% \mathrm{CI} 0.47 \text { to } 2.05 \\
\mathrm{p}=0.95\end{array}$ \\
\hline
\end{tabular}

ACS, acute coronary syndrome; CV, cardiovascular; DAPT, dual antiplatelet therapy; GUSTO, Global Utilization of Streptokinase and Tissue Plasminogen Activator for Occluded Arteries; ISTH, International Society on Thrombosis and Haemostasis; MACCE, major adverse cardiac and cerebrovascular events; MACE, major adverse cardiovascular events; MI, myocardial infarction; SCAD, stable coronary artery disease; ST, stent thrombosis; STEEPLE, Safety and Efficacy of Enoxaparin in PCI Patients, an International Randomised Evaluation; STEMI, STelevation myocardial infarction; TIMI, thrombolysis in myocardial infarction.

period following discontinuation of thienopyridine treatment. ${ }^{25}$ In a posthoc analysis, extended DAPT duration was associated with significantly increased non-CV $(0.9 \%$ vs $0.5 \%, \mathrm{p}=0.01)$ but not $\mathrm{CV}$ death $(1.0 \%$ vs $1.0 \%$, $\mathrm{p}=0.97$ ) rates throughout the randomised period. ${ }^{30}$ The rates of fatal bleeding $(0.2 \%$ vs $0.1 \%, \mathrm{p}=0.81)$ and death related to any prior bleeding $(0.3 \%$ vs $0.2 \%, \mathrm{p}=0.36)$ were similar between both treatment arms. ${ }^{30}$ Cancer-related deaths were more frequent in patients with extended DAPT treatment $(0.6 \%$ vs $0.3 \%, \mathrm{p}=0.02)$ and were rarely related to bleeding. ${ }^{30}$ However, rates of cancer occurring over the randomised period $(2.0 \%$ vs $1.6 \%, \mathrm{p}=0.12)$ or after exclusion of patients with cancer diagnosed before enrolment $(0.4 \%$ vs $0.3 \%, \mathrm{p}=0.16)$ were similar between both treatment groups. ${ }^{30}$ Overall, findings of the DAPT study suggest that continuation of DAPT beyond 1year after DES implantation might be considered in selected patients at low ischaemic and bleeding risks to reduce the rates of ST and MI, at the expense of an increased risk of bleeding.

The evidence derived from RCTs addressing different DAPT strategies after newer generation DES implantation has been recently combined in several large meta-analyses. ${ }^{31-36}$ Shorter (3-6 months) DAPT courses have been associated with similar rates of MACE, ${ }^{34} 36$ all-cause death, ${ }^{31-34}{ }^{36} \mathrm{CV}$ death, $,{ }^{31-3336} \mathrm{MI},{ }^{31-34}{ }^{36} \mathrm{ST},{ }^{31-34} 36$ or repeat revascularisation, ${ }^{32} 3336$ but with reduced rates of major bleeding ${ }^{31-3436}$ compared with 12-month DAPT. Conversely, extended (18-48 months) DAPT durations have been associated with similar rates of MACE, ${ }^{34}$ all-cause death, ${ }^{32-34} \mathrm{CV}$ death, ${ }^{31-33}$ and repeat revascularisation, ${ }^{32}$ significantly reduced rates of $\mathrm{MI}^{31-34}$ and $\mathrm{ST},{ }^{31-34}$ and increased rates of major bleeding ${ }^{31-34}$ compared with shorter (6-12 months) DAPT durations. Although the DAPT study ${ }^{25}$ and two subsequent meta-analyses ${ }^{31-33}$ showed that extended DAPT duration beyond 1 year after DES may reduce the risk of MI and ST, it has been associated with increased mortality due to increased risk of non-CV mortality not offset by a reduction in CV mortality. However, a recent large meta-analysis including 69644 patients undergoing stent implantation did not demonstrate an association between extended DAPT duration and all-cause, CV or non-CV mortality compared with aspirin alone or short DAPT duration ( $\leq 6$ months)..$^{35}$

A personalised approach considering the balance between the ischaemic benefit and the bleeding risk 
according to the patient's clinical profile is currently advocated. For most of patients with stable CAD receiving contemporary DES, a short-term DAPT strategy $(\leq 6$ months) seems a reasonable approach, and may be considered the default therapy in the absence of an increased ischaemic risk. The clinical decision to extend DAPT duration beyond 1 year (18-48 months) after stent implantation requires a personalised evaluation to weigh up ischaemic benefits (lower risk of MI and ST) and risks (increased risk of major bleeding and non-CV death). However, further research is warranted to determine the optimal selection of patients who may derive benefit from extended DAPT duration after stent implantation.

Lifelong daily low-dose aspirin $(75-150 \mathrm{mg}$ ) is currently recommended for secondary prevention of patients undergoing PCI for stable CAD (class I). ${ }^{236}$ Clopidogrel (75 mg daily) is indicated as an alternative therapy in case of aspirin intolerance (class I) ${ }^{2}$ Current European Society of Cardiology and American Heart Association/ American College of Cardiology guidelines recommend $\mathrm{P}_{12}$ receptor inhibitor therapy with clopidogrel $(75 \mathrm{mg}$ daily) for a minimum duration of 1 month after BMS (class I) and 6 months after DES implantation (class I) for patients with stable CAD undergoing PCI. ${ }^{236}$ Due to the current lack of evidence in patients with stable CAD, the use of potent $\mathrm{P}_{2} \mathrm{Y}_{12}$ receptor antagonists, prasugrel or ticagrelor, is not recommended in low-risk elective PCI (class III), but may be considered in specific high-risk elective conditions, such as left main coronary artery PCI or patients at high risk of ST or with diabetes (class IIb). ${ }^{2}$ Premature discontinuation of $\mathrm{P}_{2} \mathrm{Y}_{12}$ receptor therapy after 3-6 months following DES implantation may be considered in patients deemed at high bleeding risk or who develop significant bleeding (class IIb). ${ }^{356}$ In patients at high ischaemic risk after BMS or DES implantation who have tolerated DAPT without bleeding and who are not at high bleeding risk, continuation of DAPT with clopidogrel for longer than 1 month in patients treated with BMS or longer than 6 months in patients treated with DES may be reasonable (class IIb) ${ }^{36}$ (figure 1).

The concept of DAPT will be challenged during the next years by several ongoing RCTs that will explore novel strategies using $\mathrm{P}_{2} \mathrm{Y}_{12}$ receptor inhibitors, clopidogrel (STOPDAPT-2 (NCT02619760), SMART-CHOICE (NCT02079194)) or ticagrelor (GLOBAL LEADERS (NCT01813435), TWILIGHT (NCT02270242)), as single antiplatelet therapy after a short-term (1 or 3 months) DAPT duration after newer generation DES. GLOBAL LEADERS, the largest ongoing trial to date (16 001 patients enrolled), is a multicentre, openlabel, randomised study investigating the superiority of a 23-month ticagrelor monotherapy (after a 1-month DAPT course combining aspirin and ticagrelor) over a conventional 12-month DAPT duration consisting of aspirin and clopidogrel (stable CAD) or ticagrelor (ACS) followed by an additional 12-month course of aspirin monotherapy with respect to the composite endpoint of all-cause mortality or non-fatal MI at 2 years in all-comers patients undergoing PCI with the uniform use of a newer generation DES. Similarly, TWILIGHT is a largescale randomised, double-blind, placebo-controlled trial that will assess the efficacy and safety of ticagrelor monotherapy (after a 3-month DAPT course combining aspirin and ticagrelor) compared with standard 12-month DAPT with aspirin and ticagrelor in up to 9000 high-risk patients with stable CAD or ACS undergoing PCI with DES. The primary hypothesis of the trial is that ticagrelor monotherapy will be superior to DAPT with respect to rates of major bleeding, while maintaining non-inferiority for the risk of ischaemic events. These trials will provide novel insights with respect to the potential role of ticagrelor monotherapy as an alternative for longterm platelet inhibition in a broad population of patients undergoing PCI with DES.

Additionally, large all-comers trials are currently evaluating the safety and efficacy of an abbreviated 1-month DAPT duration compared with standard DAPT duration (6-12 months) in high bleeding risk patients undergoing PCI with newer generation DES (SENIOR (NCT02099617), MASTER DAPT (NCT03023020)). The highly anticipated results of these studies focused on patients who have been traditionally excluded from randomised trials on DAPT may provide robust randomised evidence to support a short DAPT regimen for high bleeding risk patients treated with newer generation DES in contemporary practice.

\section{CABG surgery}

Antiplatelet therapy with aspirin, preferably when initiated within 24 hours after CABG, has been shown to significantly improve early postoperative saphenous vein graft patency and reduce major adverse ischaemic events in patients undergoing surgical revascularisation. ${ }^{37-39}$ While aspirin administration remains a class I indication, the benefits of combined aspirin and clopidogrel therapy after CABG remain controversial. ${ }^{6}$ In a large meta-analysis including 25728 patients after CABG, early saphenous vein graft occlusion (RR $0.59,95 \%$ CI 0.43 to $0.82, \mathrm{p}=0.02)$ and mortality rates $(0.8 \%$ vs $1.9 \%$, RR 0.38 , $95 \%$ CI 0.26 to $0.57, \mathrm{p}<0.0001$ ) were significantly reduced among patients receiving aspirin and clopidogrel compared with those treated with aspirin alone, whereas rates of perioperative angina or MI were similar between the two treatment groups (RR 0.60, 95\% CI 0.31 to 1.14 , $\mathrm{p}=0.12) .{ }^{40}$ However, patients treated with DAPT showed a marginally increased risk of major bleeding, compared with those treated with aspirin alone (RR 1.17, 95\% CI 1.00 to $1.37, \mathrm{p}=0.05) .{ }^{40}$ In a pooled subgroup analysis of patients undergoing off-pump CABG, combined aspirin and clopidogrel therapy significantly reduced perioperative MI and saphenous vein graft occlusion rates by $68 \%$ and $55 \%$, respectively. ${ }^{40}$ In another meta-analysis, antiplatelet monotherapy was associated with increased rates of early graft occlusion compared with DAPT $(7.7 \%$ vs $5.0 \%$, OR $1.59,95 \%$ CI 1.16 to $2.17, \mathrm{p}=0.005) .{ }^{41}$ These findings were mainly driven by significantly increased 
vein graft occlusion rates in patients treated with single antiplatelet therapy $(10.8 \%$ vs $6.6 \%$, OR $1.70,95 \%$ CI 1.20 to $2.40, \mathrm{p}=0.003)$, whereas no beneficial effect was demonstrated on arterial graft occlusion rates in the DAPT group (2.8\% vs $2.7 \%$, OR $1.17,95 \%$ CI 0.54 to $2.56, \mathrm{p}=0.84) .{ }^{41}$ These data might suggest the potential benefits of DAPT after CABG on vein graft, but not arterial graft, patency, at the expense of a marginally increased risk of bleeding events $(6.3 \%$ vs $5.8 \%$, OR 0.98 , $\mathrm{p}=0.85) .{ }^{41}$ A prospective observational study compared short- (30 days) versus long-term (mean duration 34 months) administration of clopidogrel in addition to aspirin among 591 consecutive patients undergoing isolated off-pump CABG. ${ }^{42}$ After a mean follow-up of 38 months, postoperative clopidogrel administration was independently associated with reduced MACE (sudden cardiac death, MI or coronary reintervention) (OR $0.20,95 \%$ CI 0.10 to 0.45 ) and symptom recurrence (OR $0.30,95 \%$ CI 0.15 to 0.99$)$ rates $\left(\mathrm{p}<0.0001\right.$ for both). ${ }^{42}$ However, there was no significant difference in the incidence of individual ischaemic endpoints (all-cause death, sudden cardiac death, MI, congestive heart failure, coronary reintervention or angina) between short- and longterm clopidogrel administration after multivariate analysis. ${ }^{42}$ In the prevention of Coronary arteRY bypaSS occlusion After off-pump procedures (CRYSSA) single-centre RCT including 300 patients who underwent off-pump CABG, combined aspirin and clopidogrel therapy was shown to significantly reduce vein graft $(7.4 \%$ vs $13.1 \%, \mathrm{p}=0.04)$ but not arterial graft occlusion rates $(4.9 \%$ vs $4.9 \%)$ and major adverse ischaemic events (death, MI, PCI or stroke) $(4.7 \%$ vs $9.3 \%, p=0.1)$, compared with aspirin alone. ${ }^{43}$ The rates of minor or major bleeding events $(3.3 \%$ vs $2.6 \%$ ) were similar between the two treatment arms.

For patients treated with DAPT after PCI who subsequently undergo $\mathrm{CABG}, \mathrm{P}_{2} \mathrm{Y}_{12}$ receptor antagonist therapy should be resumed postoperatively to complete the recommended DAPT duration (class I) ${ }^{6}$ In patients with stable CAD undergoing CABG, DAPT with clopidogrel (initiated early in the postoperative period) for 12 months may be considered to improve vein graft patency $(\text { class IIb })^{6}$ (figure 1). Due to the lack of clinical evidence in patients with stable CAD, the use of potent P2Y 12 receptor inhibitors (prasugrel or ticagrelor) is currently not recommended. Nevertheless, the efficacy and safety of an intensified platelet inhibition using ticagrelor after CABG are currently investigated in the Ticagrelor in $C A B G$ (TiCAB) trial (NCT01755520), an ongoing, multicentre, double-blind, double-dummy, randomised trial that will compare ticagrelor with aspirin for the prevention of MACE within 12 months after CABG. The study will randomise 3850 patients undergoing CABG in a 1:1 fashion to either ticagrelor $90 \mathrm{mg}$ twice daily or aspirin $100 \mathrm{mg}$ once daily. Of note, the study medication will be started within 24 hours after surgery and maintained for 12 months. The primary endpoint will be a composite of CV death, MI, stroke and repeat revascularisation at 12 months after CABG.

\section{ACUTE CORONARY SYNDROME}

Antiplatelet therapy with aspirin remains the cornerstone of pharmacological therapy for patients with ACS, irrespective of the clinical setting (non-ST-elevation ACS (NSTE-ACS), or ST-elevation myocardial infarction (STEMI)) and the patient management strategy (conservative treatment, PCI or CABG).$^{56}$ In a meta-analysis of 16 secondary prevention trials comparing longterm aspirin versus control therapy in 17000 high-risk patients, aspirin significantly reduced MACE by $20 \%$ (absolute benefit 1\%/year), non-fatal stroke by $19 \%$ and $\mathrm{CV}$ mortality by $9 \% .{ }^{1}$ However, there is ongoing debate regarding the optimal maintenance dose of aspirin for secondary prevention of CV events in patients with ACS. In the Clopidogrel and Aspirin Optimal Dose Usage to Reduce Recurrent Events-Seventh Organization to Assess Strategies in Ischemic Syndromes (CURRENT-OASIS 7) trial including 25086 patients with ACS, no significant difference was observed between high-dose (300-325 mg daily) and low-dose (75-100 mg daily) aspirin with regard to the composite endpoint of $\mathrm{CV}$ death, MI or stroke at 30 days ( $4.2 \%$ vs $4.4 \%$, HR $0.97,95 \%$ CI 0.86 to $1.09, \mathrm{p}=0.61$ ), irrespective of the management strategy (conservative treatment or PCI). ${ }^{44}$ Low-dose aspirin was associated with significant lower rates of major gastrointestinal bleeding $(0.2 \%$ vs $0.4 \%, \mathrm{p}=0.04)$, whereas high-dose aspirin showed no reduction in rates of the primary endpoint $(4.1 \%$ vs $4.2 \%$, HR $0.98,95 \%$ CI 0.84 to 1.13 , $\mathrm{p}=0.76)$ or major bleeding $(1.5 \%$ vs $1.3 \%$, HR 1.18 , $95 \%$ CI 0.92 to $1.53, \mathrm{p}=0.20$ ) in the subgroup of patients undergoing PCI. ${ }^{44}$ Furthermore, a subanalysis of the Platelet Inhibition and Patient Outcomes (PLATO) trial has recently suggested a reduced efficacy of ticagrelor versus clopidogrel in ACS patients treated with high aspirin doses, whereas ticagrelor appeared to be more effective than clopidogrel in decreasing CV events in patients on low-dose aspirin. ${ }^{46}$ Although the exact mechanism underlying the potential interaction between ticagrelor and higher aspirin doses remains unclear, a proposed hypothesis is linked to the level of $\mathrm{P}_{2} \mathrm{Y}_{12}$ inhibition and the potential prothrombotic effects of high-dose aspirin through the suppression of prostacyclin. Overall, data regarding the use of aspirin for secondary prevention of CV events in patients with ACS demonstrate a general lack of benefit of high maintenance doses of aspirin owing to the absence of a dose-response relationship between increasing aspirin dose and improved efficacy, and a higher incidence of gastrointestinal bleeding with increasing aspirin doses. Compared with aspirin monotherapy, DAPT provides significant incremental reduction of CV events in patients with ACS and is considered the cornerstone of pharmacological treatment, irrespective of the management strategy.

\section{Conservative treatment}

In the Clopidogrel in Unstable Angina to Prevent Recurrent Events (CURE) study comparing clopidogrel versus placebo in 12562 patients with ACS, $64 \%$ of patients were 
treated conservatively and did not undergo revascularisation after randomisation. ${ }^{47}$ DAPT combining aspirin and clopidogrel for 3-12 months was associated with a significant reduction of the primary composite endpoint (CV death, non-fatal MI or stroke) compared with placebo (9.3\% vs $11.4 \%$, RR $0.80,95 \%$ CI 0.72 to 0.90 , p $<0.001)$, at the expense of an increased risk of major bleeding in the clopidogrel group $(3.7 \%$ vs $2.7 \%$, RR $1.38, \mathrm{p}=0.001) .{ }^{47}$ Nevertheless, rates of life-threatening bleeding $(2.1 \%$ vs $1.8 \%, \mathrm{p}=0.13)$, including fatal bleeding and haemorrhagic stroke, were similar between the two treatment groups. $^{47}$

The Targeted Platelet Inhibition to Clarify the Optimal Strategy to Medically Manage Acute Coronary Syndromes (TRILOGY ACS) trial compared the efficacy and safety of prasugrel versus clopidogrel among 7243 patients $<75$ years with ACS receiving aspirin and undergoing conservative management. ${ }^{48}$ At a median follow-up of 17 months, no differences with regard to the primary composite endpoint (CV death, non-fatal MI or stroke) ( $13.9 \%$ vs $16 \%$, HR $0.91,95 \%$ CI 0.79 to $1.05, \mathrm{p}=0.21)$ and severe or intracranial bleeding were observed between the two treatment groups. ${ }^{48}$ The prespecified analysis that was performed to account for multiple recurrent ischemic events suggested a lower risk in patients $<75$ years in the prasugrel group (HR $0.85,95 \%$ CI 0.72 to $1.00, \mathrm{p}=0.04){ }^{48}$ Conversely, in the subgroup analysis of the PLATO trial including 5216 patients (28\% of the total population) managed conservatively, the clinical benefit of ticagrelor over clopidogrel was consistent with the results in the overall study population, with a $15 \%$ reduction in the composite primary endpoint $(12.0 \%$ vs $14.3 \%$, HR $0.85,95 \%$ CI 0.73 to $1.00, \mathrm{p}=0.04$ ) and a $25 \%$ reduction in all-cause mortality $(6.1 \%$ vs $8.2 \%$, HR 0.75 , $95 \%$ CI 0.61 to $0.93, \mathrm{p}=0.01)$, despite a numerically higher incidence of total major bleeding $(11.9 \%$ vs $10.3 \%$, HR $1.17,95 \%$ CI 0.98 to $1.39, \mathrm{p}=0.08$ ) and nonCABG-related major bleeding $(4.0 \%$ vs $3.1 \%$, HR $1.30,95 \%$ CI 0.95 to $1.77, \mathrm{p}=0.10$ ) with ticagrelor than with clopidogrel. ${ }^{49}$ These results confirm the potential clinical superiority of an intense platelet inhibition with ticagrelor (but not prasugrel) over clopidogrel for selected patients with ACS undergoing conservative management.

Current guidelines recommend DAPT combining low-dose aspirin (75-100 mg/day) and a $\mathrm{P}_{12}$ receptor inhibitor (clopidogrel or ticagrelor) during 12 months for patients with ACS managed conservatively (class I). ${ }^{56}$ Although the use of ticagrelor over clopidogrel seems reasonable (class IIa), ${ }^{6}$ the administration of prasugrel is not recommended (class III). ${ }^{5}$ Long-term DAPT may be considered for selected patients who tolerated the DAPT regimen during the first 12 months without bleeding (class IIb) ${ }^{6}$ (figure 2 ).

Notwithstanding, contemporary randomised data on the optimal DAPT strategy for medically managed patients with ACS are scarce. Patients with ACS undergoing conservative management represent a large and highly heterogeneous population, and the generalisation of recommendations on the duration of DAPT for patients with ACS treated with PCI to this specific patient subgroup is questionable in view of the currently available evidence. Future research to determine the optimal antiplatelet regimen and duration in conservatively managed patients with ACS is therefore warranted.

\section{Percutaneous coronary intervention}

Intense $\mathrm{P}_{2} \mathrm{Y}_{12}$ receptor inhibition for patients with ACS undergoing PCI has been shown to improve clinical outcomes in RCTs comparing DAPT regimens with clopidogrel versus placebo, ${ }^{50}$ prasugrel versus clopidogrel, ${ }^{51}$ or ticagrelor versus clopidogrel. ${ }^{52}$

In the subgroup of 2658 patients with NSTE-ACS undergoing PCI in the CURE study, pretreatment (median 6 days) followed by long-term therapy (median 10 days) with clopidogrel and aspirin was associated with a $31 \%$ reduction in the composite endpoint of CV death or MI at 30 days $(8.8 \%$ vs $12.6 \%$, RR 0.69 , 95\% CI 0.54 to $0.87, \mathrm{p}=0.002)$ compared with aspirin and placebo. ${ }^{50}$ After PCI, most patients $(>80 \%)$ in both arms (including in the aspirin alone arm) received open-label thienopyridine for about 4 weeks, after which study drug was restarted for a mean duration of 8 months. ${ }^{50}$ The Trial to Assess Improvement in Therapeutic Outcomes by Optimising Platelet Inhibition with Prasugrel-Thrombolysis in Myocardial Infarction (TRITON-TIMI) 38 compared the clinical benefits of prasugrel versus clopidogrel for a duration of 6-15 months in combination with aspirin among 13608 patients with moderate-to-high-risk ACS scheduled to undergo PCI. ${ }^{51}$ As compared with clopidogrel, prasugrel significantly reduced the risk of the primary composite endpoint (CV death, non-fatal MI or stroke) by $19 \%(9.9 \%$ vs $12.1 \%$, HR $0.81,95 \%$ CI 0.73 to 0.90$)$, MI by $24 \%(7.3 \%$ vs $9.5 \%$, HR $0.76,95 \%$ CI 0.67 to 0.85 ), urgent target-vessel revascularisation (TVR) by $34 \%(2.5 \%$ vs $3.7 \%$, HR $0.66,95 \%$ CI 0.54 to 0.81$)$ and ST by $52 \%$ ( $1.1 \%$ vs $2.4 \%$, HR $0.48,95 \%$ CI 0.36 to 0.64$)$ at 12 months $(\mathrm{p}<0.001$ for all $)$, but increased the risk of nonCABG-related thrombolysis in myocardial infarction (TIMI) major bleeding (2.4\% vs $1.8 \%$, HR 1.32 , $95 \%$ CI 1.03 to $1.6, \mathrm{p}=0.03$ ), including fatal bleeding. ${ }^{51}$ Overall mortality did not differ significantly between treatment groups $(3.0 \%$ vs $3.2 \%$, HR $0.95,95 \%$ CI 0.78 to $1.16, \mathrm{p}=0.64) .^{52}$ In a posthoc subgroup analysis of patients with age $\geq 75$ years, body weight $<60 \mathrm{~kg}$ or history of stroke or transient ischaemic attack (TIA), prasugrel was associated with reduced clinical benefit with regard to the primary efficacy endpoint $(16.1 \%$ vs $16.0 \%$, HR $1.02,95 \%$ CI 0.84 to $1.24, \mathrm{p}=0.83$ ) and increased risk of nonCABG-related TIMI major bleeding $(4.3 \%$ vs $3.3 \%$, HR $1.42,95 \%$ CI 0.93 to $2.15, \mathrm{p}=0.10$ ) when compared with the overall cohort, resulting in less net clinical benefit or in clinical harm compared with clopidogrel. ${ }^{51}$

In the PLATO trial, ticagrelor was compared with clopidogrel in addition to aspirin in 18624 patients with ACS. ${ }^{52}$ At 12-month follow-up, ticagrelor significantly reduced the risk of the primary composite endpoint (CV 


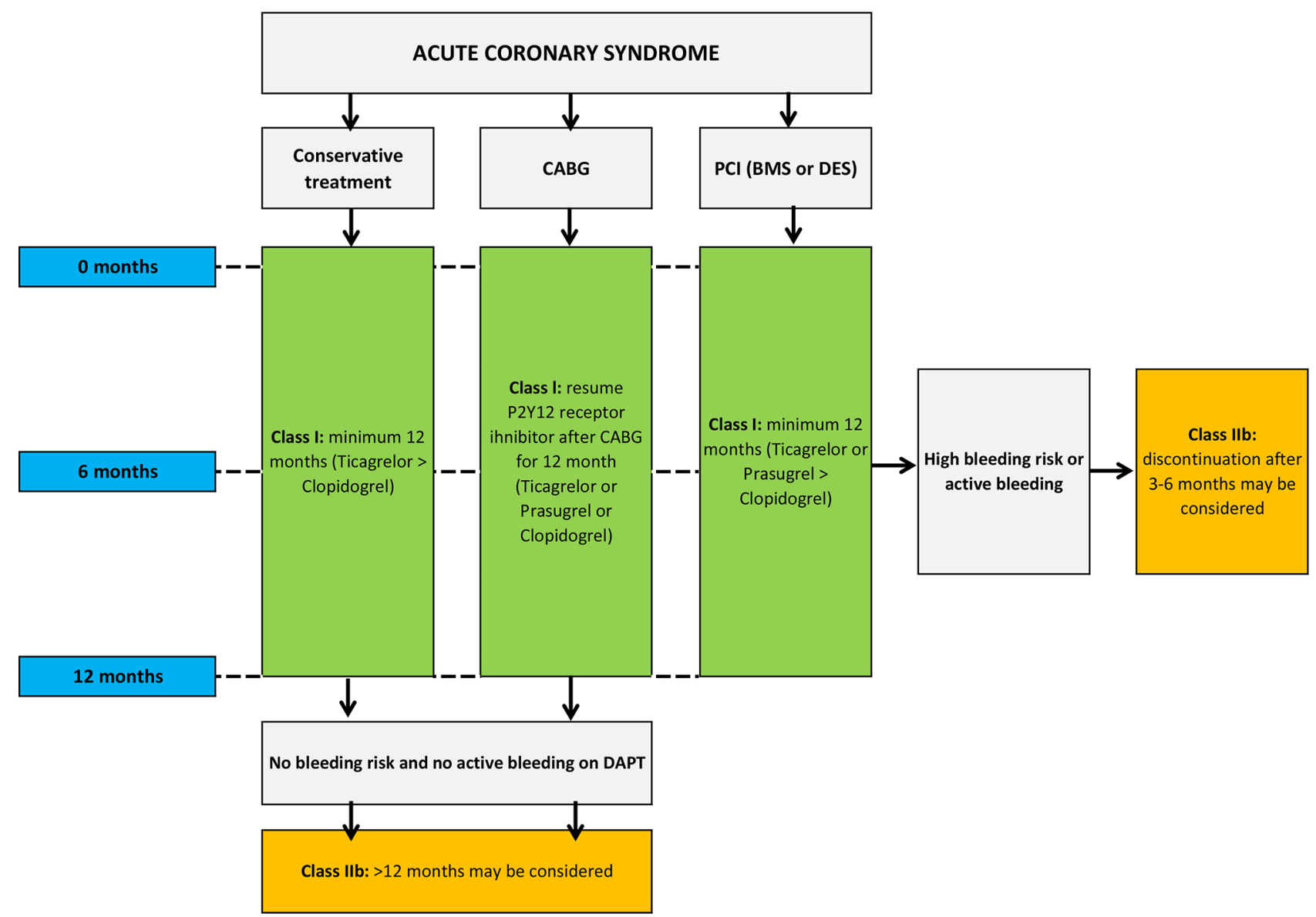

Figure $2 \mathrm{P}_{2} \mathrm{Y}_{12}$ receptor inhibitor therapy for secondary prevention of patients with acute coronary syndrome. BMS, bare metal stent; CABG, coronary artery bypass graft surgery; DAPT, dual antiplatelet therapy; DES, drug-eluting stent; PCI, percutaneous coronary intervention.

death, non-fatal MI or stroke) by $16 \%(9.8 \%$ vs $11.7 \%$, HR $0.84,95 \%$ CI 0.77 to 0.92 , p $<0.001)$, MI by $16 \%(5.8 \%$ vs $6.9 \%$, HR $0.84,95 \%$ CI 0.75 to $0.95, \mathrm{p}=0.005)$, all-cause $(4.5 \%$ vs $5.9 \%$, HR $0.78,95 \%$ CI 0.69 to $0.89, \mathrm{p}<0.001)$ and CV mortality $(4.0 \%$ vs $5.1 \%$, HR $0.79,95 \%$ CI 0.69 to $0.91, \mathrm{p}=0.001$ ) by $22 \%$ and $21 \%$ respectively, compared with clopidogrel. ${ }^{52}$ Although no significant difference was observed in the overall incidence of major bleeding ( $11.6 \%$ vs $11.2 \%$, HR $1.04,95 \%$ CI 0.95 to 1.13 , $\mathrm{p}=0.43$ ), ticagrelor was associated with significantly increased rates of nonCABG-related major bleeding $(4.5 \%$ vs $3.8 \%$, HR $1.19,95 \%$ CI 1.02 to $1.38, p=0.03$ ). The significant differences in TRITON-TIMI $38^{51}$ and PLATO ${ }^{52}$ study designs preclude any interpretation from indirect comparisons between the two potent oral $\mathrm{P}_{2} \mathrm{Y}_{12}$ receptor inhibitors. Recently, the efficacy and safety of ticagrelor versus prasugrel in patients with STEMI treated with primary PCI were compared in the Comparison of Prasugrel and Ticagrelor in the Treatment of Acute Myocardial Infarction (PRAGUE18) study, which was prematurely terminated for futility after inclusion of 1230 patients. ${ }^{53}$ The occurrence of the primary composite endpoint (death, MI, TVR, stroke, serious bleeding requiring transfusion or prolonging hospitalisation) at 7 days was not significantly different between patients receiving prasugrel and ticagrelor
( $4.0 \%$ vs $4.1 \%$, OR $0.98,95 \%$ CI 0.55 to $1.73, \mathrm{p}=0.94)$ and no significant difference was found in any of the components of the primary composite endpoint. ${ }^{53}$ The occurrence of the secondary composite endpoint (CV death, non-fatal MI or stroke) within 30 days was similar among patients treated with prasugrel or ticagrelor $(2.7 \%$ vs $2.5 \%$, OR $1.06,95 \%$ CI 0.53 to $2.15, \mathrm{p}=0.86) .{ }^{53}$ Despite being small and underpowered, this first head-to-head comparison of prasugrel and ticagrelor in patients with STEMI undergoing primary PCI does not support the superiority of one of the potent $\mathrm{P}_{2} \mathrm{Y}_{12}$ receptor inhibitors for the prevention of ischaemic and bleeding events.

Current guidelines recommend DAPT combining long-term, low-dose aspirin (75-100 mg/day) and a P2Y 12 receptor inhibitor therapy (clopidogrel, ticagrelor or prasugrel) for at least 12 months in patients with ACS undergoing PCI, irrespective of the stent type (BMS or DES) (class I). ${ }^{56}$ The use of potent $\mathrm{P}_{2} \mathrm{Y}_{12}$ receptor antagonists (ticagrelor for patients at moderate-to-high risk of ischaemic events, including patients who were pretreated with clopidogrel, or prasugrel) should be preferred over clopidogrel (patients who cannot receive ticagrelor or prasugrel, or who require long-term OAC therapy). ${ }^{5}{ }^{6}$ Prasugrel is not recommended for patients in whom coronary anatomy is not known (class III), ${ }^{5}$ or with history of 
stroke or TIA (class III). ${ }^{5}$ In patients at high bleeding risk or who develop significant bleeding, premature discontinuation of DAPT after $3^{5}$ or $6^{56}$ months may be reasonable (class IIb). In patients with low bleeding risk who have tolerated DAPT during 12 months without bleeding complications, long-term continuation of DAPT may be considered (class IIb) ${ }^{6}$ (figure 2).

Nevertheless, current recommendations on the optimal duration of DAPT in patients with ACS are not based on contemporary randomised evidence. ${ }^{50-52}$ Notably, the median duration of DAPT in the pivotal trials evaluating the efficacy and safety of the combination of aspirin and a P2Y 12 receptor inhibitor in patients with ACS was 9-12 months with clopidogrel, ${ }^{50} 14.5$ months with prasugre ${ }^{51}$ and only 9.2 months with ticagrelor. ${ }^{52}$ Furthermore, no randomised evidence focused on patients with ACS is currently available comparing shorter versus standard or extended DAPT durations with respect to clinical outcomes in contemporary practice, whereas randomised data from prespecified ACS subgroup analyses of recent trials including patients treated with newer generation DES have consistently shown that shorter durations of DAPT (3-6 months) were non-inferior to $12^{181922-245455}$ or $24^{20}$ months with respect to composite endpoints of $\mathrm{CV}$ events or CV events plus major bleeding. The optimal duration of DAPT in patients with ACS treated with DES remains therefore still under debate. Large-scale randomised trials (REDUCE (NCT02118870), SMARTDATE (NCT01701453)) are currently investigating the efficacy and safety of a short-term DAPT strategy (3 months and 6 months, respectively) compared with the recommended 12-month DAPT duration in patients with ACS undergoing PCI with newer generation DES and should provide novel insights into this important clinical dilemma during the next years.

\section{CABG surgery}

There is little evidence concerning the benefits and risks of a combined aspirin and $\mathrm{P}_{2} \mathrm{Y}_{12}$ receptor inhibitor therapy for patients with ACS undergoing surgical revascularisation owing to major concerns concerning the risk of perioperative major bleeding complications with intense antiplatelet inhibition. In the subgroup of patients undergoing CABG in the CURE study $(n=2072$, $16.5 \%$ ), clopidogrel in addition to aspirin was associated with a $11 \%$ relative risk reduction in rates of the primary composite endpoint (CV death, MI or stroke) compared with placebo ( $14.5 \%$ vs $16.2 \%$, RR $0.89,95 \%$ CI 0.71 to $1.11)$, despite marginally increased rates of life-threatening bleeding events in the clopidogrel arm $(5.6 \%$ vs $4.2 \%$, RR $1.30,95 \%$ CI 0.91 to 1.95$).^{55}$ These findings were consistent with the treatment effect observed in the overall study population and suggest that the benefits of a DAPT with clopidogrel in patients with ACS may outweigh the risks among patients who undergo CABG during the initial hospitalisation. Data concerning more potent $\mathrm{P}_{2} \mathrm{Y}_{12}$ receptor antagonists, prasugrel or ticagrelor, are currently limited to posthoc analyses of RCTs. In a subgroup analysis of patients with ACS who underwent isolated CABG in the TRITON-TIMI 38 study $(n=346)$, all-cause mortality within 30 days was significantly reduced with prasugrel compared with clopidogrel (2.3\% vs $8.7 \%$, OR $0.26, p=0.025$ ), despite significantly higher mean chest tube blood loss at 12 hours and platelet transfusion rates, and marginally increased rates of red blood cell transfusion and surgical re-exploration for bleeding in the prasugrel arm. ${ }^{56}$ In the subgroup of patients with ACS who underwent CABG within 7 days after the last study drug intake in the PLATO trial $(\mathrm{n}=1261,6.8 \%)$, ticagrelor was associated with significantly reduced rates of total mortality $(4.7 \%$ vs $9.7 \%$, HR $0.49,95 \%$ CI 0.32 to $0.77, \mathrm{p}<0.01)$ and $\mathrm{CV}$ death $(4.1 \%$ vs $7.9 \%$, HR 0.52 , $95 \%$ CI 0.32 to $0.85, \mathrm{p}<0.01)$ compared with clopidogrel. ${ }^{57}$ The relative risk reduction of the primary composite endpoint (CV death, MI or stroke) at 12 months in the CABG subgroup (10.6\% with ticagrelor vs $13.1 \%$ with clopidogrel, HR $0.84,95 \%$ CI 0.60 to $1.16, \mathrm{p}=0.29$ ) was consistent with the results of the overall trial, without significant difference in CABG-related major bleeding rates between treatment arms. ${ }^{57}$

For patients with ACS (NSTE-ACS or STEMI) treated with DAPT and undergoing surgical revascularisation, current guidelines recommend to resume the $\mathrm{P}_{12}$ receptor inhibitor therapy after CABG to complete the 12-month DAPT duration after ACS (class I) ${ }^{356}$ (figure 2). Due to the lack of randomised evidence, the appropriate antiplatelet regimen after CABG remains an area of controversy, and large, multicentre, randomised clinical trials are needed to definitively investigate the role of DAPT in patients with ACS after CABG.

\section{SPECIAL POPULATIONS AND CONDITIONS High-risk patients with prior acute MI}

Current guidelines recommend DAPT with a $\mathrm{P}_{5} \mathrm{Y}_{12}$ receptor antagonist for 1 year after acute $\mathrm{MI}^{3}{ }^{3}{ }^{12}$ However, patients with prior MI remain at increased long-term risk for ischaemic events (CV death, MI or stroke) during the subsequent years. ${ }^{58}$ The potential benefit of extended duration of DAPT beyond 1 year for the long-term secondary prevention of CV events after MI remains a matter of debate. In a posthoc analysis of the CHARISMA trial, high-risk patients with documented prior MI, ischaemic stroke or symptomatic PAD ( $\mathrm{n}=9478)$ were shown to derive significant benefit with regard to subsequent ischaemic events from longterm intensification of antiplatelet therapy beyond aspirin alone. After a median follow-up duration of 27.6 months, rates of the primary composite endpoint (CV death, MI or stroke) were significantly lower in the DAPT arm combining aspirin and clopidogrel than in the aspirin arm $(7.3 \%$ vs $8.8 \%$, HR $0.83,95 \%$ CI 0.72 to $0.96, \mathrm{p}=0.01$ ) without significant differences in severe bleeding rates $(1.7 \%$ vs $1.5 \%$, HR $1.12,95 \%$ CI 0.81 to $1.53, \mathrm{p}=0.50$ ). However, the incidence of moderate bleeding was significantly increased in the aspirin plus 
clopidogrel group (2.0\% vs $1.3 \%$, HR $1.60,95 \%$ CI 1.16 to $2.20, \mathrm{p}=0.004)$.

The Prevention of Cardiovascular Events in Patients with Prior Heart Attack Using Ticagrelor Compared with Placebo on a Background of Aspirin-Thrombolysis in Myocardial Infarction 54 (PEGASUS-TIMI 54) trial is the largest RCT to date evaluating the benefits of long-term DAPT for secondary prevention in high-risk patients with prior MI. PEGASUS-TIMI 54 randomised 21162 patients with stable CAD, prior MI 1-3 years before inclusion and at high CV risk ( $\geq 1$ high risk criteria: age $\geq 65$ years, diabetes, second MI, multivessel CAD or chronic kidney disease) to aspirin monotherapy (75-150 mg daily) versus DAPT combining aspirin and ticagrelor (60 or $90 \mathrm{mg}$ twice daily) ${ }^{59}$ After a median follow-up of 33 months, the two ticagrelor doses in addition to aspirin were associated with significantly reduced rates of the primary composite efficacy endpoint (CV death, MI or stroke) as compared with placebo $(7.85 \%, 7.77 \%$ and $9.04 \%$ at 3 years in ticagrelor $90 \mathrm{mg}$ twice daily, ticagrelor $60 \mathrm{mg}$ twice daily and placebo groups, respectively; HR ticagrelor $90 \mathrm{mg}$ vs placebo $0.85,95 \%$ CI 0.75 to $0.96, p=0.008$; HR ticagrelor $60 \mathrm{mg}$ vs placebo $0.84,95 \%$ CI 0.74 to $0.95, p=0.004) .{ }^{59}$ Rates of TIMI major bleeding were higher with ticagrelor than with placebo $(2.6 \%, 2.3 \%$ and $1.06 \%$ at 3 years, respectively; HR ticagrelor $90 \mathrm{mg}$ vs placebo $2.69,95 \%$ CI 1.96 to $3.70, \mathrm{p}<0.001$; HR ticagrelor $60 \mathrm{mg}$ vs placebo $2.32,95 \% \mathrm{CI}$ 1.68 to $3.21, \mathrm{p}<0.001$ ), whereas rates of fatal bleeding or non-fatal intracranial haemorrhage did not differ significantly between either ticagrelor dose group and placebo $\left(0.63 \%, 0.71 \%\right.$ and $0.6 \%$ at 3 years, respectively).$^{59}$ These findings were recently confirmed in a large meta-analysis including 33435 high-risk patients with history of MI. ${ }^{60}$ After a mean follow-up of 31 months, prolonged DAPT was associated with significantly reduced rates of MACE (6.4 vs $7.5 \%$, RR $0.78,95 \%$ CI 0.67 to $0.90, \mathrm{p}=0.001$ ), CV death (2.3 vs $2.6 \%$, RR $0.85,95 \%$ CI 0.74 to 0.98 , $\mathrm{p}=0.03$ ), MI (RR $0.70,95 \%$ CI 0.55 to $0.88, \mathrm{p}=0.003$ ), stroke (RR 0.81, 95\% CI 0.68 to $0.97, \mathrm{p}=0.02$ ) and ST (RR $0.50,95 \%$ CI 0.28 to $0.89, \mathrm{p}=0.02$ ), when compared with aspirin alone, with no significant increase in non-CV (RR $1.03,95 \%$ CI 0.86 to $1.23, p=0.76$ ) and all-cause mortality (RR 0.92, 95\% CI 0.83 to $1.03, \mathrm{p}=0.13$ ) ${ }^{60}$ Extended DAPT was associated with increased risk of major bleeding (1.85 vs $1.09 \%$, RR $1.73,95 \%$ CI 1.19 to $2.50, \mathrm{p}=0.004$ ) but not fatal bleeding ( 0.14 vs $0.17 \%$, RR $0.91,95 \%$ CI 0.53 to $1.58, \mathrm{p}=0.75){ }^{60}$

In a posthoc analysis of PEGASUS-TIMI 54, the net clinical benefit of ticagrelor for long-term secondary prevention in high-risk patients with prior MI seemed more pronounced in patients continuing on, or restarting after only a brief interruption, $\mathrm{P}_{2} \mathrm{Y}_{12}$ inhibition, when compared with patients with stable CAD (no MACE for $>2$ years after MI) and off $\mathrm{P}_{2} \mathrm{Y}_{12}$ inhibitor therapy for $>1$ year, irrespective of time from MI. ${ }^{61}$ For clinicians considering a strategy of prolonged DAPT in high-risk patients postMI, these data suggest greater benefit in the continuation of $\mathrm{P}_{12} \mathrm{Y}_{12}$ inhibitor therapy without interruption after MI, rather than reinitiating such therapy in patients who have remained stable for an extended period.

In patients at high ischaemic risk after acute MI, continuation of $\mathrm{P}_{2} \mathrm{Y}_{12}$ receptor inhibitor therapy (preferably with ticagrelor $60 \mathrm{mg}$ twice daily) in addition to low-dose aspirin beyond 1 year may be considered after careful assessment of the patient ischaemic and bleeding risks (class IIb) (figures 1 and 2). ${ }^{56}$ However, future studies and development of practical clinical tools are warranted to clarify further the optimal selection of post-MI patients most likely to derive clinical benefit from long-term DAPT after MI.

\section{Patients requiring long-term oral anticoagulant therapy}

Approximately $6-8 \%$ of patients undergoing PCI have a concomitant indication for long-term OAC with a vitamin $\mathrm{K}$ antagonist (VKA) or a non-VKA oral anticoagulant (NOAC) for conditions such as atrial fibrillation (AF), left ventricular thrombus, mechanical valve prosthesis or venous thromboembolism. Current evidence to guide the management of patients undergoing PCI and requiring long-term OAC practice remains limited. Compared with VKA alone, dual therapy (clopidogrel and VKA) and triple therapy (VKA and DAPT with a $\mathrm{P}_{12}$ receptor inhibitor) in patients with AF following MI or PCI have been shown to increase the risk of major fatal and non-fatal bleeding. ${ }^{62}$ Omission of aspirin while maintaining P2Y ${ }_{12}$ receptor antagonist has been evaluated in the What is the Optimal antiplatElet and anticoagulant therapy in patients with OAC and coronary Sten Ting (WOEST) trial, an open-label, multicentre RCT including 573 patients receiving oral anticoagulant therapy (AF or flutter $69 \%$ ) and candidates for PCI (DES 65\%) for stable CAD or ACS $(25 \%-30 \%)$, who were assigned to clopidogrel alone (dual therapy) or clopidogrel plus aspirin (triple therapy) for 1 month after BMS and 1 year after DES. ${ }^{63}$ The rates of the primary safety outcome (any bleeding episode) at 1 year were significantly reduced in the dual therapy arm, as compared with the triple therapy arm $(19.4 \%$ vs $44.4 \%$, HR $0.36,95 \%$ CI 0.26 to $0.50, \mathrm{p}<0.0001$ ), mainly driven by significant reductions in non-intracranial bleedings. ${ }^{63}$ Despite being small and underpowered for hard clinical outcomes, the trial showed a significant reduction of the secondary composite ischaemic endpoint (death, MI, stroke, TVR or ST) in the dual therapy group $(11.1 \%$ vs $17.6 \%$, HR $0.60,95 \%$ CI 0.38 to $0.94, p=0.025$ ) as compared with patients on triple therapy. ${ }^{63}$ These data suggest the potential superiority of dual antithrombotic therapy with regard to occurrence of major bleedings compared with triple therapy among patients undergoing PCI and who are candidates for long-term OAC, without evidence of increased risk of thrombotic events by omission of aspirin.

The Intracoronary Stenting and Antithrombotic Regimen-Testing of a 6 Week Versus a 6Month Clopidogrel Treatment Regimen in Patients With Concomitant Aspirin and Oral Anticoagulant Therapy Following Drug-Eluting Stenting (ISAR-TRIPLE) trial enrolled 614 patients receiving OAC 
and who underwent DES implantation to 6-week versus 6-month clopidogrel therapy in addition to aspirin. ${ }^{64}$ The rates of the primary composite endpoint (death, MI, definite ST, stroke or TIMI major bleeding) at 9 months were similar between the two treatment groups $(9.8 \%$ vs $8.8 \%$, HR $1.14,95 \%$ CI 0.68 to $1.91, \mathrm{p}=0.63) .{ }^{64}$ Despite low event rates, there were no significant differences for the secondary combined ischaemic endpoint (CV death, MI, definite ST and ischaemic stroke) $(4.0 \%$ vs $4.3 \%$, HR $0.93,95 \%$ CI 0.43 to $2.05, \mathrm{p}=0.87$ ) or the secondary bleeding endpoint of TIMI major bleeding ( $5.3 \%$ vs $4.0 \%$, HR $1.35,95 \%$ CI 0.64 to $2.84, \mathrm{p}=0.44) .{ }^{64}$

Recently, the Open-Label, Randomised, Controlled, Multicenter Study Exploring Two Treatment Strategies of Rivaroxaban and a Dose-Adjusted Oral Vitamin K Antagonist Treatment Strategy in Subjects with Atrial Fibrillation who Undergo Percutaneous Coronary Intervention (PIONEER AF-PCI) trial randomly assigned 2124 patients with non-valvular AF who underwent PCI to receive in a 1:1:1 ratio low-dose rivaroxaban ( $15 \mathrm{mg}$ once daily) plus a $\mathrm{P}_{2} \mathrm{Y}_{12}$ inhibitor for 12 months (group 1$)$, very-low-dose rivaroxaban $(2.5 \mathrm{mg}$
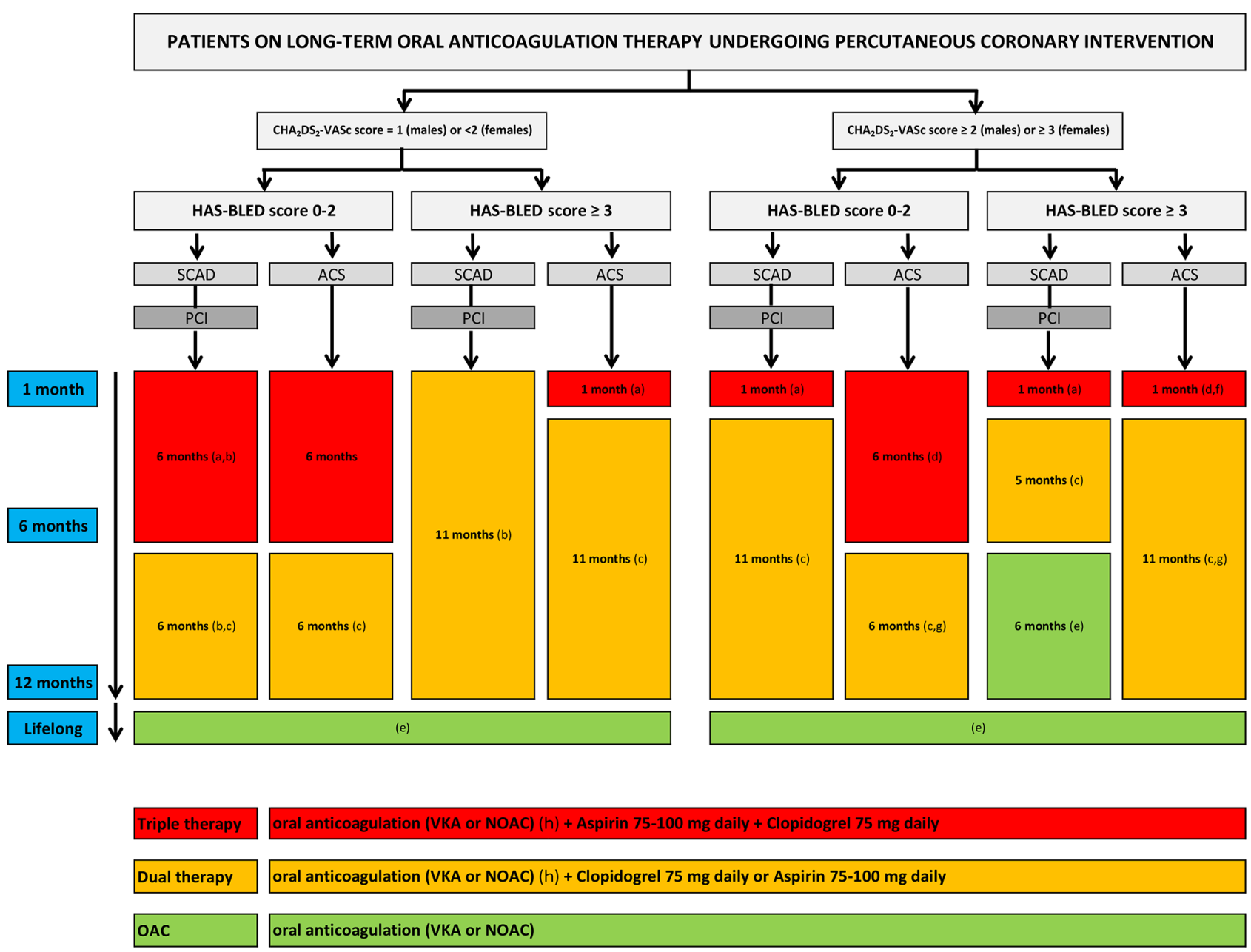

Figure 3 Antithrombotic strategies in patients on long-term oral anticoagulation therapy undergoing percutaneous coronary intervention. ACS: acute coronary syndrome; NOAC: non-vitamin K antagonist oral anticoagulant; PCl: percutaneous coronary intervention; OAC: oral anticoagulation; SCAD: stable coronary artery disease; VKA: vitamin K antagonist. ${ }^{a}$ Dual therapy with oral anticoagulation and single antiplatelet therapy (aspirin or clopidogrel) may be considered in selected patients at low ischaemic risk. ${ }^{b}$ Dual antiplatelet therapy (aspirin and clopidogrel) may be considered. ${ }^{\circ}$ Dual therapy with oral anticoagulation and aspirin (as an alternative to clopidogrel) may be considered. ${ }^{\mathrm{d} D u a l}$ therapy with oral anticoagulation and single antiplatelet therapy (aspirin or clopidogrel) up to 12 months may be considered in selected patients, particularly for patients managed medically or undergoing CABG. ${ }^{e}$ Dual therapy with oral anticoagulation and a single antiplatelet agent (aspirin or clopidogrel) may be considered in patients at very high risk of coronary events. 'Dual therapy with oral anticoagulation and clopidogrel may be considered in selected patients at low ischaemic risk. ${ }^{9}$ Triple therapy with oral anticoagulation and dual antiplatelet therapy (aspirin and clopidogrel) may be considered up to 12 months in very selected patients at high risk of ischaemic events: prior stent thrombosis on adequate antiplatelet therapy, left main coronary artery or last remaining patent coronary artery stenting, multiple stenting in proximal coronary artery segments, two stents bifurcation treatment, or diffuse multivessel coronary artery disease, particularly in patients with diabetes mellitus. ${ }^{\mathrm{h}} \mathrm{Choice}$ and dose of oral anticoagulants used in combination with antiplatelet therapy: Vitamin K antagonist (International Normalised Ratio 2-2,5); Dabigatran $110 \mathrm{mg}$ once daily; Rivaroxaban 15 mg once daily; Apixaban 2,5 mg twice daily; Edoxaban 30 mg (or $15 \mathrm{mg}$ ) once daily. 


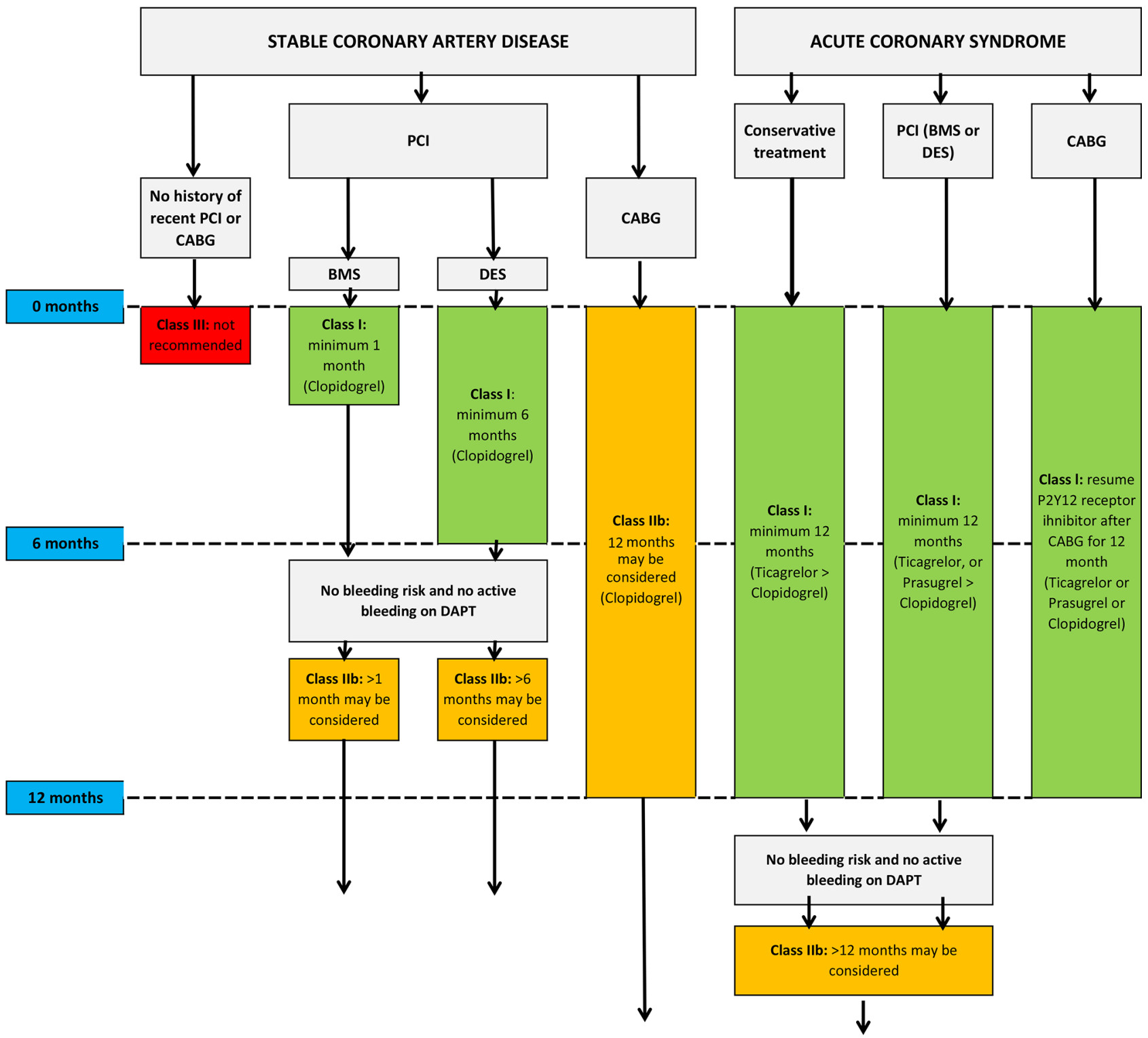

Figure $4 \mathrm{P}_{2} \mathrm{Y}_{12}$ receptor inhibitor therapy for secondary prevention of patients with coronary artery disease. BMS, bare metal stent; CABG, coronary artery bypass graft surgery; DAPT, dual antiplatelet therapy; DES, drug-eluting stent; MI, myocardial infarction; $\mathrm{PCl}$, percutaneous coronary intervention.

twice daily) plus DAPT for 1, 6 or 12 months (group 2), or standard therapy with a dose-adjusted VKA plus DAPT for 1,6 or 12 months (group 3). ${ }^{65}$ At 12 months, rates of the primary safety endpoint (clinically significant bleeding) were significantly lower in the two groups receiving rivaroxaban compared with the standard therapy group ( $16.8 \%$ in group 1, $18.0 \%$ in group 2 and $26.7 \%$ in group 3; HR for group 1 vs group 30.59 , 95\% CI 0.47 to 0.76 , $\mathrm{p}<0.001$; HR for group 2 vs group $30.63,95 \%$ CI 0.50 to $0.80, \mathrm{p}<0.001) .{ }^{65}$ The secondary combined ischaemic endpoint (CV death, MI or stroke) occurred similarly in the three treatment groups $(6.5 \%$ in group $1,5.6 \%$ in group 2 and $6.0 \%$ in group 3; p values for all comparisons non-significant). ${ }^{65}$ Notwithstanding, the absence of a 'WOEST-like' control arm and the broad CIs observed for individual components of the secondary endpoint may preclude any definitive conclusions concerning the risk of thrombotic events of a low-dose or very low-dose rivaroxaban strategy combined with $\mathrm{P}_{12} \mathrm{Y}_{12}$ inhibitor monotherapy or DAPT. Future randomised studies adequately powered for efficacy endpoints are needed to confirm the potential superiority of an antithrombotic strategy combining a low-dose NOAC and a $\mathrm{P}_{2} \mathrm{Y}_{12}$ receptor inhibitor monotherapy over triple antithrombotic therapy for patients with non-valvular AF undergoing PCI.

Until further data from large RCTs become available, current consensus statements recommend an individualised approach and advocate to limit as possible the duration of triple therapy, depending on the clinical setting (stable $\mathrm{CAD}$ vs ACS), the thromboembolic risk $\left(\mathrm{CHA}_{2} \mathrm{DS}_{2}-\mathrm{VASc}\right.$ score) and the bleeding risk (eg, HAS-BLED score $)^{666}$ (figure 3). The indication for OAC should be carefully reassessed in patients requiring DAPT and anticoagulant therapy continued only if a compelling indication is 
present. The dose intensity of OAC should be carefully monitored with a target INR of 2.0-2.5 in patients treated with VKA (except patients with mitral mechanical prosthetic valves) and time in therapeutic window of $>70 \%$. In patients treated with an NOAC, the lowest dose evaluated for stroke prevention should be used. In the absence of randomised evidence with respect to safety and efficacy, the use of prasugrel or ticagrelor as part of triple therapy should currently be avoided. ${ }^{566}$ Nevertheless, the optimal management strategy of patients undergoing PCI and requiring long-term OAC represents an unmet clinical need in contemporary practice. Future research focused on this high-risk patient population and adequately designed and powered to determine the antithrombotic regimen and duration that provides the optimal balance between efficacy and safety is warranted.

\section{CONCLUSION}

Despite a large body of randomized evidence, the optimal regimen and duration of DAPT for secondary prevention of patients with CAD remains a matter of intense debate. Future studies are needed to better identify patients who may derive benefit from either shortened or prolonged DAPT durations to improve outcomes while minimising bleeding risks. Until more evidence becomes available, the optimal DAPT regimen and duration for patients with $\mathrm{CAD}$ requires a tailored approach based on the patient clinical presentation, baseline risk profile and management strategy (figure 4). Several ongoing largescale randomised trials are currently investigating novel antiplatelet strategies and will contribute to refining the optimal regimen and duration of DAPT for secondary prevention of patients with $\mathrm{CAD}$ in the near future.

Acknowledgements The authors warmly thank Christian Chervet for his help for the figure's layout.

Contributors Dr JFI (corresponding author) attests that the coauthors have participated in the redaction of this manuscript.

Competing interests None declared.

Provenance and peer review Not commissioned; externally peer reviewed.

Data sharing statement There are no additional data available for this paper.

Open Access This is an Open Access article distributed in accordance with the Creative Commons Attribution Non Commercial (CC BY-NC 4.0) license, which permits others to distribute, remix, adapt, build upon this work non-commercially, and license their derivative works on different terms, provided the original work is properly cited and the use is non-commercial. See: http://creativecommons.org/ licenses/by-nc/4.0/

(c) Article author(s) (or their employer(s) unless otherwise stated in the text of the article) 2017. All rights reserved. No commercial use is permitted unless otherwise expressly granted.

\section{REFERENCES}

1. Baigent $\mathrm{C}$, Blackwell L, Collins R, et al. Aspirin in the primary and secondary prevention of vascular disease: collaborative metaanalysis of individual participant data from randomised trials. Lancet 2009;373:1849-60.

2. Montalescot G, Sechtem U, Achenbach S, et al. ESC guidelines on the management of stable coronary artery disease. Eur Heart $J$ 2013;2013:2949-3003.
3. Cardiovascular P, Eapci I, France JC, et al. ESC/EACTS Guidelines on myocardial revascularization. Eur Heart $J$ 2014;35:2541-619.

4. Valgimigli M, Patialiakas A, Thury A, et al. Zotarolimus-eluting versus bare-metal stents in uncertain drug-eluting stent candidates. J Am Coll Cardiol 2015;65:805-15.

5. Roffi M, Patrono C, Collet J-P, et al. 2015 ESC Guidelines for the management of acute coronary syndromes in patients presenting without persistent ST-segment elevation. Eur Heart $J$ 2016;37:267-315.

6. Levine GN, Bates ER, Bittl JA, et al. ACC/AHA guideline focused update on duration of dual antiplatelet therapy in patients with coronary artery disease: a report of the American College of Cardiology/American Heart Association Task Force on Clinical Practice Guidelines. J Am Coll Cardiol 2016;2016:1082-115.

7. CAPRIE Steering Committee. A randomised, blinded, trial of clopidogrel versus aspirin in patients at risk of ischaemic events (CAPRIE). Lancet 1996;348:1329-39.

8. Bhatt DL, Fox KA, Hacke W, et al. Clopidogrel and aspirin versus aspirin alone for the prevention of atherothrombotic events. $N$ Engl $J$ Med 2006;354:1706-17.

9. Bhatt DL, Flather MD, Hacke W, et al. Patients with prior myocardial infarction, stroke, or symptomatic peripheral arterial disease in the CHARISMA trial. J Am Coll Cardiol 2007;49:1982-8.

10. Schömig A, Neumann FJ, Kastrati A, et al. A randomized comparison of antiplatelet and anticoagulant therapy after the placement of coronary-artery stents. N Engl J Med 1996;334:1084-9.

11. Bertrand ME, Legrand V, Boland J, et al. Randomized multicenter comparison of conventional anticoagulation versus antiplatelet therapy in unplanned and elective coronary stenting. The full anticoagulation versus aspirin and ticlopidine (fantastic) study. Circulation 1998;98:1597-603.

12. Leon MB, Baim DS, Popma JJ, et al. A clinical trial comparing three antithrombotic-drug regimens after coronary-artery stenting. Stent Anticoagulation Restenosis Study Investigators. N Engl J Med 1998;339:1665-71.

13. Urban P, Macaya C, Rupprecht HJ, et al. Randomized evaluation of anticoagulation versus antiplatelet therapy after coronary stent implantation in high-risk patients: the multicenter aspirin and ticlopidine trial after intracoronary stenting (MATTIS). Circulation 1998;98:2126-32.

14. Ndrepepa G, Schuster T, Hadamitzky M, et al. Validation of the bleeding academic research consortium definition of bleeding in patients with coronary artery disease undergoing percutaneous coronary intervention. Circulation 2012;125:1424-31.

15. Mehran R, Pocock S, Nikolsky E, et al. Impact of bleeding on mortality after percutaneous coronary intervention results from a patient-level pooled analysis of the REPLACE-2 (randomized evaluation of PCl linking angiomax to reduced clinical events), ACUITY (acute catheterization and urgent intervention triage strategy), and HORIZONS-AMI (harmonizing outcomes with revascularization and stents in acute myocardial infarction) trials. JACC Cardiovasc Interv 2011;4:654-64.

16. Steinhubl SR, Berger PB, Mann JT, et al. Early and sustained dual oral antiplatelet therapy following percutaneous coronary intervention: a randomized controlled trial. JAMA 2002;288:2411-20.

17. Stefanini GG, Taniwaki M, Windecker S. Coronary stents: novel developments. Heart 2014;100:1051-61.

18. Gwon HC, Hahn JY, Park KW, et al. Six-month versus 12-month dual antiplatelet therapy after implantation of drug-eluting stents: the Efficacy of Xience/Promus Versus Cypher to Reduce Late Loss After Stenting (EXCELLENT) randomized, multicenter study. Circulation 2012;125:505-13.

19. Kim BK, Hong MK, Shin DH, et al. A new strategy for discontinuation of dual antiplatelet therapy: the RESET Trial (REal Safety and Efficacy of 3-month dual antiplatelet Therapy following Endeavor zotarolimuseluting stent implantation). J Am Coll Cardiol 2012;60:1340-8.

20. Valgimigli M, Campo G, Monti M, et al. Short- versus long-term duration of dual-antiplatelet therapy after coronary stenting: a randomized multicenter trial. Circulation 2012;125:2015-26.

21. Feres F Costa RA Abizaid A, et al. Three vs twelve months of dual antiplatelet therapy after zotarolimus-eluting stents. JAMA 2013;310:2510-22.

22. Colombo A, Chieffo A, Frasheri A, et al. Second-generation drugeluting stent implantation followed by 6 - Versus 12 -month dual antiplatelet therapy. J Am Coll Cardiol 2014;64:2086-97.

23. Gilard M, Barragan P, Noryani AA, et al. 6- versus 24-month dual antiplatelet therapy after implantation of drug-eluting stents in patients nonresistant to aspirin: the randomized, multicenter ITALIC trial. J Am Coll Cardiol 2015;65:777-86.

24. Schulz-Schüpke S, Byrne RA, Ten Berg JM, et al. ISAR-SAFE: a randomized, double-blind, placebo-controlled trial of 6 vs. 12 
months of clopidogrel therapy after drug-eluting stenting. Eur Heart J 2015;36:1252-63.

25. Mauri L, Kereiakes DJ, Yeh RW, et al. Twelve or 30 months of dual antiplatelet therapy after drug-eluting stents. N Engl J Med 2014;371:2155-66.

26. Park SJ, Park DW, Kim YH, et al. Duration of dual antiplatelet therapy after implantation of drug-eluting stents. N Engl J Med 2010;362:1374-82.

27. Lee CW, Ahn JM, Park DW, et al. Optimal duration of dual antiplatelet therapy after drug-eluting stent implantation: a randomized, controlled trial. Circulation 2014;129:304-12.

28. Collet JP, Silvain J, Barthélémy O, et al. Dual-antiplatelet treatment beyond 1 year after drug-eluting stent implantation (ARCTICInterruption): a randomised trial. Lancet 2014;384:1577-85.

29. Helft G, Steg PG, Le Feuvre C, et al. Stopping or continuing clopidogrel 12 months after drug-eluting stent placement: the OPTIDUAL randomized trial. Eur Heart J 2016;37:365-74

30. Mauri L, Elmariah S, Yeh RW, et al. Causes of late mortality with dual antiplatelet therapy after coronary stents. Eur Heart $J$ 2016;37:378-85.

31. Giustino G, Baber U, Sartori S, et al. Duration of dual antiplatelet therapy after drug-eluting stent implantation. J Am Coll Cardiol 2015;65:1298-310.

32. Navarese EP, Andreotti F, Schulze V, et al. Optimal duration of dual antiplatelet therapy after percutaneous coronary intervention with drug eluting stents: meta-analysis of randomised controlled trials. BMJ 2015;350:h1618.

33. D'Ascenzo F, Moretti C, Bianco M, et al. Meta-analysis of the duration of dual antiplatelet therapy in patients treated with secondgeneration drug-eluting stents. Am J Cardiol 2016;117:1714-23.

34. Bittl JA, Baber U, Bradley SM, et al. Duration of dual antiplatelet therapy: a systematic review for the 2016 acc/aha guideline focused update on duration of dual antiplatelet therapy in patients with coronary artery disease duration of dapt erc systematic review report. Circulation 2016;134:156-78.

35. Elmariah S, Mauri L, Doros G, et al. Extended duration dual antiplatelet therapy and mortality: a systematic review and metaanalysis. Lancet 2015;385:792-8.

36. Palmerini T, Sangiorgi D, Valgimigli M, et al. Short- versus long-term dual antiplatelet therapy after drug-eluting stent implantation: an individual patient data pairwise and network meta-analysis. J Am Coll Cardiol 2015;65:1092-102.

37. Lorenz RL, Schacky CV, Weber M, et al. Improved aortocoronary bypass patency by low-dose aspirin (100 mg daily). Effects on platelet aggregation and thromboxane formation. Lancet 1984;1:1261-4.

38. Goldman S, Copeland J, Moritz T, et al. Improvement in early saphenous vein graft patency after coronary artery bypass surgery with antiplatelet therapy: results of a Veterans Administration Cooperative Study. Circulation 1988;77:1324-32.

39. Bhatt DL, Chew DP, Hirsch AT, et al. Prior Cardiac Surgery. Circulation 2001;103:363-8.

40. Deo SV, Dunlay SM, Shah IK, et al. Dual anti-platelet therapy after coronary artery bypass grafting: is there any benefit? A systematic review and meta-analysis. J Card Surg 2013;28:109-16.

41. Nocerino AG, Achenbach S, Taylor AJ. Meta-analysis of effect of single versus dual antiplatelet therapy on early patency of bypass conduits after coronary artery bypass grafting. Am J Cardiol 2013;112:1576-9.

42. Gurbuz AT, Zia AA, Vuran AC, et al. Postoperative clopidogrel improves mid-term outcome after off-pump coronary artery bypass graft surgery: a prospective study. Eur $J$ Cardiothorac Surg 2006;29:190-5.

43. Mannacio VA, Di Tommaso L, Antignan A, et al. Aspirin plus clopidogrel for optimal platelet inhibition following off-pump coronary artery bypass surgery: results from the CRYSSA (prevention of Coronary arteRY bypaSS occlusion after off-pump procedures) randomised study. Heart 2012;98:1710-5.

44. Mehta SR, Bassand JP, Chrolavicius S, et al. Dose comparisons of clopidogrel and aspirin in acute coronary syndromes. N Engl J Med 2010;363:930-42

45. Mehta SR, Tanguay JF, Eikelboom JW, et al. Double-dose versus standard-dose clopidogrel and high-dose versus low-dose aspirin in individuals undergoing percutaneous coronary intervention for acute coronary syndromes (CURRENT-OASIS 7): a randomised factorial trial. Lancet 2010;376:1233-43.

46. Berger JS. Aspirin, clopidogrel, and ticagrelor in acute coronary syndromes. Am J Cardiol 2013;112:737-45.

47. Yusuf S, Zhao F, Mehta SR, et al. Effects of clopidogrel in addition to aspirin in patients with acute coronary syndromes without STsegment elevation. N Engl J Med 2001;345:494-502.
48. Roe MT, Armstrong PW, Fox KA, et al. Prasugrel versus clopidogre for acute coronary syndromes without revascularization. $N$ Engl J Med 2012;367:1297-309.

49. James SK, Roe MT, Cannon CP, et al. Ticagrelor versus clopidogrel in patients with acute coronary syndromes intended for non-invasive management: substudy from prospective randomised PLATelet inhibition and patient Outcomes (PLATO) trial. BMJ 2011;342:d3527.

50. Mehta SR, Yusuf S, Peters RJ, et al. Effects of pretreatment with clopidogrel and aspirin followed by long-term therapy in patients undergoing percutaneous coronary intervention: the PCl-CURE study. Lancet 2001:358:527-33.

51. Wiviott SD, Braunwald $\mathrm{E}, \mathrm{McC}$ abe $\mathrm{CH}$, et al. Prasugrel versus clopidogrel in patients with acute coronary syndromes. N Engl J Med 2007;357:2001-15.

52. Wallentin L, Becker RC, Budaj A, et al. Ticagrelor versus clopidogrel in patients with acute coronary syndromes. $N$ Engl J Med 2009;361:1045-57.

53. Motovska Z, Hlinomaz O, Miklik R, et al. Prasugrel versus ticagrelor in patients with acute myocardial infarction treated with primary percutaneous coronary intervention: multicenter randomized PRAGUE-18 study. Circulation 2016;134:1603-12.

54. Silber S, Kirtane AJ, Belardi JA, et al. Lack of association between dual antiplatelet therapy use and stent thrombosis between 1 and 12 months following resolute zotarolimus-eluting stent implantation. Eur Heart J 2014;35:1949-56.

55. Fox KA, Mehta SR, Peters R, et al. Benefits and risks of the combination of clopidogrel and aspirin in patients undergoing surgical revascularization for non-ST-elevation acute coronary syndrome: the clopidogrel in unstable angina to prevent recurrent ischemic events (CURE) trial. Circulation 2004;110:1202-8.

56. Smith PK, Goodnough LT, Levy JH, et al. Mortality benefit with prasugrel in the TRITON-TIMI 38 coronary artery bypass grafting cohort: risk-adjusted retrospective data analysis. J Am Coll Cardiol 2012;60:388-96

57. Held C, Asenblad N, Bassand JP, et al. Ticagrelor versus clopidogrel in patients with acute coronary syndromes undergoing coronary artery bypass surgery: results from the PLATO (Platelet Inhibition and Patient Outcomes) trial. J Am Coll Cardiol 2011:57:672-84.

58. Jernberg T, Hasvold P, Henriksson M, et al. Cardiovascular risk in post-myocardial infarction patients: nationwide real world data demonstrate the importance of a long-term perspective. Eur Heart $J$ 2015;36:1163-70.

59. Bonaca MP, Bhatt DL, Cohen M, et al. Long-term use of ticagrelor in patients with prior myocardial infarction. $N$ Engl $J$ Med 2015;372:1791-800

60. Udell JA, Bonaca MP Collet JP, et al. Long-term dual antiplatelet therapy for secondary prevention of cardiovascular events in the subgroup of patients with previous myocardial infarction: a collaborative meta-analysis of randomized trials. Eur Heart $J$ 2016;37:390-9.

61. Bonaca MP, Bhatt DL, Steg PG, et al. Ischaemic risk and efficacy of ticagrelor in relation to time from P2Y12 inhibitor withdrawal in patients with prior myocardial infarction: insights from PEGASUSTIMI 54. Eur Heart J 2016;37:1133-42.

62. Lamberts $\mathrm{M}$, Olesen JB, Ruwald $\mathrm{MH}$, et al. Bleeding after initiation of multiple antithrombotic drugs, including triple therapy, in atrial fibrillation patients following myocardial infarction and coronary intervention: a nationwide cohort study. Circulation 2012;126:1185-93.

63. Dewilde WJ, Oirbans T, Verheugt FW, et al. Use of clopidogrel with or without aspirin in patients taking oral anticoagulant therapy and undergoing percutaneous coronary intervention: an open-label, randomised, controlled trial. Lancet 2013;381:1107-15.

64. Fiedler KA, Maeng M, Mehilli J, et al. Duration of triple therapy in patients requiring oral anticoagulation after drug-eluting stent implantation: the ISAR-TRIPLE trial. J Am Coll Cardiol 2015;65:1619-29.

65. Gibson CM, Mehran R, Bode C, et al. Prevention of bleeding in patients with atrial fibrillation undergoing PCI. N Engl J Med 2016;375:2423-34.

66. Lip GY, Windecker S, Huber K, et al. Management of antithrombotic therapy in atrial fibrillation patients presenting with acute coronary syndrome and/or undergoing percutaneous coronary or valve interventions: a joint consensus document of the European Society of Cardiology Working Group on Thrombosis, European Heart Rhythm Association (EHRA), European Association of Percutaneous Cardiovascular Interventions (EAPCI) and European Association of Acute Cardiac Care (ACCA) endorsed by the Heart Rhythm Society (HRS) and Asia-Pacific Heart Rhythm Society (APHRS). Eur Heart $J$ 2014;35:3155-79. 